\title{
Elecciones en México 2015 - 2016: Construyendo la paridad sustantiva
}

\section{Elections in Mexico 2015 - 2016: Building substantive parity}

Raquel Pacheco Avilez

Recepción: 10 de octubre de 2016 Aceptación: 08 de diciembre de 2016

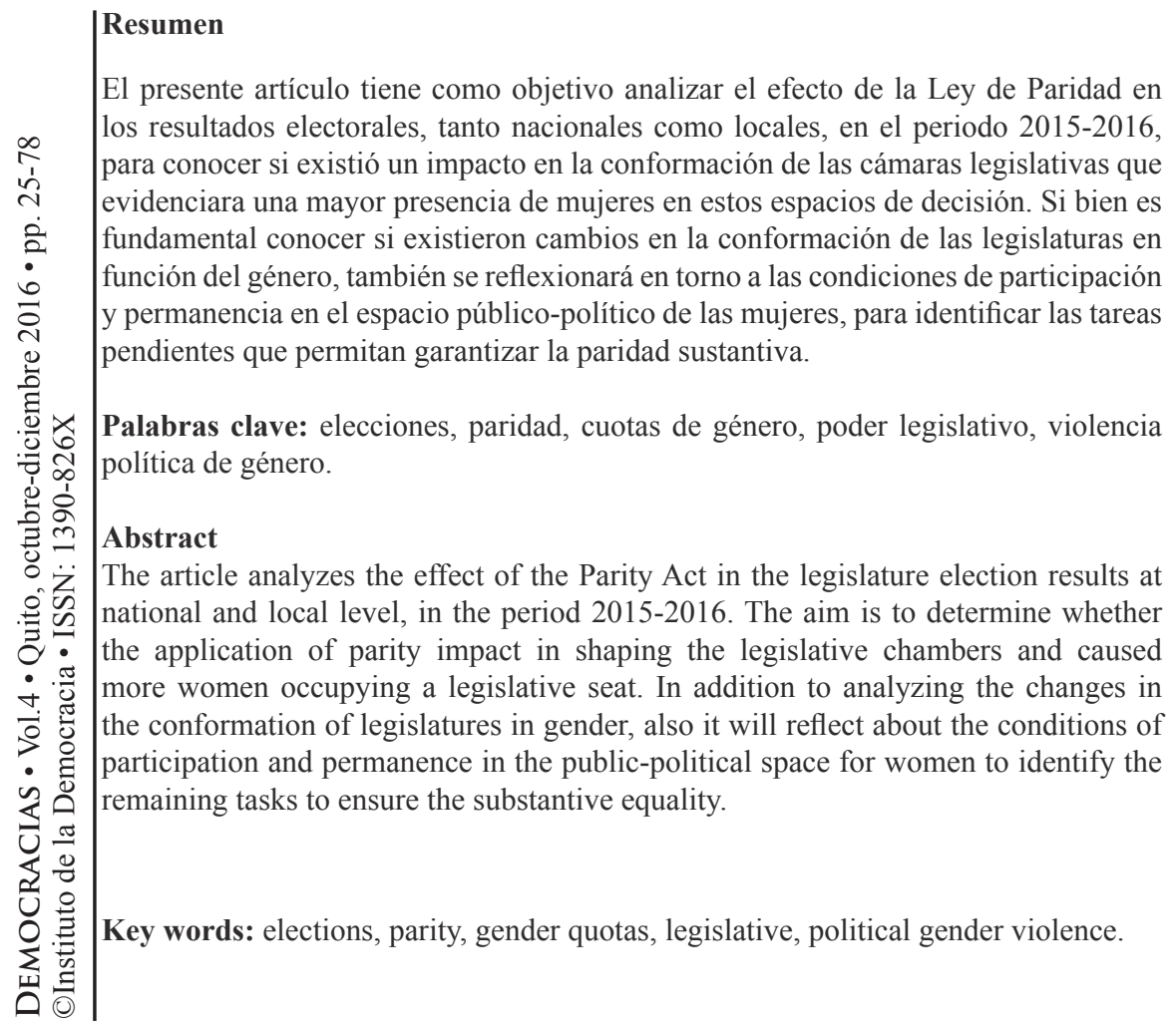




\section{Introducción}

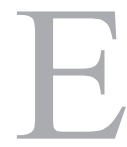

n el periodo 2015 - 2016 se llevaron a cabo procesos electorales en México tanto federales como locales. En el 2015 se renovó la Cámara de Diputados Federal (en total 500 curules: 300 de mayoría relativa y 200 de representación proporcional); y asimismo hubo elecciones locales en 17 Estados de la República para elegir Gobernadores/as, Diputados/as locales y Alcaldes/as. Mientras que en el 2016 las elecciones fueron sólo locales en 12 Estados, destaca el proceso electoral de la Ciudad de México para elegir a 60 diputados/as constituyentes.

Todos estos procesos se desarrollaron bajo una reforma al marco constitucional que estableció la paridad entre los géneros en candidaturas a legisladores federales y locales (CPEUM, Art. 41). La cual generó a su vez reformas tanto a la Ley General de Instituciones y Procedimientos Electorales (LGIPE, Arts. 7, 232, 233, 234 y 241) así como a la Ley General de Partidos Políticos (LGPP, Arts. 3 numeral 4, 25 y 73). Con esto México se sumó a otros cuatro países, Bolivia, Costa Rica, Ecuador y Nicaragua, que establecieron el principio de paridad en sus constituciones.

En este sentido, el presente artículo tiene como objetivo analizar el efecto de la Ley de Paridad en los resultados electorales, tanto nacionales como locales, en el periodo referido, para conocer si existió un impacto en la conformación de las cámaras legislativas que evidenciara una mayor presencia de mujeres en estos espacios de decisión. Si bien es fundamental conocer si existieron cambios en la conformación de las legislaturas en función del género, también se reflexionará en torno a las condiciones de participación y permanencia en el espacio público-político de las mujeres, para identificar las tareas pendientes que permitan garantizar la paridad sustantiva.

El documento se estructura en tres apartados, el primero realiza una breve exposición de la evolución normativa en materia de igualdad y equidad 
de género que va desde la primera ley de cuotas hasta la paridad. El segundo apartado, revisa los resultados electorales nacionales haciendo un análisis comparativo con procesos electorales previos que nos permita evidenciar si ha aumentado la presencia de mujeres en el legislativo nacional. El tercero, revisa los resultados electorales locales también en el legislativo, lo cual nos permitirá identificar los estados de la República que tienen paridad (50\%), los que tienen mayor participación política de mujeres (entre $40-49 \%$ de la cámara), aquellos con presencia promedio (entre 25-39\% de la cámara) y los de baja participación (-24\% de la cámara), una variable a considerar en esta sección será la pertenencia partidaria. Finalmente, se presentan las conclusiones en donde se plantea un panorama general de los principales obstáculos que aún se siguen presentando, tanto para que las mujeres tengan acceso a las candidaturas como para alcanzar el triunfo, esto es, las condiciones de competencia, para luego plantear algunas propuestas que permitan garantizar la paridad sustantiva.

\section{De las cuotas de género a la paridad}

Aquí se presenta la evolución de las leyes para garantizar la igualdad y equidad de género en el sistema electoral y de partidos de México, con especial énfasis en la reforma a la Constitución y LEGIPE del 2014. Previo a ello, se establece el marco teórico-conceptual en el que se sustentan las diversas acciones en pro de la igualdad y equidad para la participación política de las mujeres.

Teoría de género, marco para los derechos políticos de las mujeres

Los derechos políticos de las mujeres, en específico, tienen como referente 
principal la teoría de género ${ }^{1}$, la cual nos permite identificar la situación de desigualdad entre mujeres y hombres en los diversos ámbitos sociales públicos y privados, y de manera concreta en el espacio político ${ }^{2}$. Uno de los primeros objetivos del movimiento feminista fue conseguir la igualdad de derechos, en el marco del feminismo liberal encontramos que el reclamo se basó en la exigencia del mismo estatus ontológico de ser humano como ser racional para las mujeres (Mary Wollstonecraft, John Stuart Mill y Harriet Taylor). Con este posicionamiento se pidió la igualdad de derechos y obligaciones formales, así como la participación de las mujeres en el espacio público³.

Sobre esta base surge durante el siglo XIX el movimiento sufragista que luchó por el derecho de las mujeres al voto y a ser electas, pero también exigieron reformas legales que les permitieran derechos relacionados con el matrimonio, el divorcio, leyes de custodia de los infantes, la propiedad, el trabajo y la educación. Si bien se fueron alcanzando ciertos derechos tanto sociales como políticos, hay que señalar que el sufragio femenino se obtuvo casi en todos los países hasta el siglo XX. En 1948, por medio de la Declaración Universal de los Derechos Humanos artículo 21, se dio el reconocimiento internacional del derecho de las mujeres a participar en el ámbito de la política como un derecho humano fundamental estableciendo que: toda persona tiene derecho a participar en el gobierno de su país.

1 La categoría de género, de naturaleza política y académica, se incorporó en la segunda mitad del siglo XX a las ciencias sociales, a partir de la discusión feminista en torno a los orígenes de la subordinación femenina y de las relaciones de poder, dominación y opresión sobre las mujeres. Los debates de la época giraban alrededor de dos modelos explicativos: el determinismo biológico y el análisis sociocultural de las diferencias (Lamas, 1986).

2 "El sello masculino del proyecto ilustrado no permitió la inclusión de las mujeres en el pacto social, de tal manera que la Declaración de los Derechos del Hombre y del Ciudadano (1789) reafirmó la exclusión de las mujeres como titulares de derechos, negándoles la categoría de ciudadanía y, por ende, los derechos inherentes a dicha condición". (Pateman, 1995; Canterla, 2002)

3 Es importante señalar que además del feminismo liberal encontramos otras expresiones y tipos como el marxista, socialista, radical, negro, entre otros, todos ellos han contribuido a la lucha por los derechos de las mujeres. 
En América Latina, el primer país en reconocer el voto femenino fue Ecuador en 1929, mientras que el último fue Paraguay en 1961, es relevante señalar que transcurrieron treinta y dos años para que en la región se garantizara el derecho a las mujeres votar y ser elegidas. No obstante la incorporación de las mujeres al padrón de votantes, no se produjo de manera inmediata la participación femenina en los parlamentos o en los poderes ejecutivos, lo cual ha ido en detrimento del ejercicio pleno de los derechos políticos de las mujeres.

Esta desigual participación política de las mujeres ha generado un fuerte cuestionamiento sobre el tipo de calidad democrática con la que se cuenta, así como del carácter representativo de los gobiernos. Ante ello, algunas de las acciones que se fueron tomando tanto desde la normativa constitucional como en la legislación político-electoral consistió por una parte en establecer leyes en contra de la discriminación en todos los ámbitos, y por otro, de manera particular en lo político, se promovieron políticas de equidad que permitieran garantizar las mismas oportunidades para participar en la política tanto a mujeres como hombres, y así integrar la agenda pública con todas las visiones, problemáticas e intereses. 


\section{Tabla 1.}

Año de obtención del voto femenino en América Latina y el Caribe 19291961 (Por orden cronológico)

\begin{tabular}{|c|c|c|c|c|c|}
\hline PAÍS & AÑO & PAÍS & AÑO & PAÍS & AÑO \\
\hline Ecuador & 1929 & Suriname & 1948 & $\begin{array}{c}\text { San Vicente y las } \\
\text { Granadinas }\end{array}$ & 1951 \\
\hline Uruguay & 1932 & Chile & 1949 & Santa Lucía & 1951 \\
\hline Brasil & 1932 & Costa Rica & 1949 & Bolivia & 1952 \\
\hline Cuba & 1934 & $\begin{array}{c}\text { Islas Vírgenes } \\
\text { Británicas }\end{array}$ & 1950 & Guyana & 1953 \\
\hline \multicolumn{6}{|l|}{ República } \\
\hline $\begin{array}{l}\text { Domini- } \\
\text { cana }\end{array}$ & 1942 & El Salvador & 1950 & México & 1953 \\
\hline Jamaica & 1944 & Haití & 1950 & Belice & 1954 \\
\hline $\begin{array}{l}\text { Guate- } \\
\text { mala }\end{array}$ & 1946 & $\begin{array}{l}\text { Antigua y Bar- } \\
\text { buda }\end{array}$ & 1951 & Colombia & 1954 \\
\hline Panamá & 1946 & Barbados & 1951 & Honduras & 1955 \\
\hline $\begin{array}{l}\text { Trinidad y } \\
\text { Tobago }\end{array}$ & 1946 & Dominica & 1951 & Nicaragua & 1955 \\
\hline Argentina & 1947 & Granada & 1951 & Perú & 1955 \\
\hline \multirow[t]{2}{*}{ Aruba } & 1948 & $\begin{array}{c}\text { Saint Kitts y } \\
\text { Nevis }\end{array}$ & 1951 & Bahamas & 1961 \\
\hline & & & & Paraguay & 1961 \\
\hline
\end{tabular}

Fuente: CEPAL, (1999). Participación, Liderazgo y Equidad de Género en América Latina y El Caribe, Santiago de Chile.

Elaborado por: Autora. 
La traducción de estas políticas de equidad se dio a través del planteamiento de acciones afirmativas, que son un conjunto de políticas o medidas de carácter temporal que tienen como propósito acelerar la igualdad de facto entre mujeres y hombres, lo cual se logra a partir de la identificación de las desigualdades estructurales para así plantear acciones concretas que reduzcan la brecha de la desigualdad entre mujeres y hombres en todos los ámbitos. Resulta fundamental partir del hecho de que existen asimetrías profundas que relegan y discriminan a las mujeres como consecuencia de una construcción social basada en el patriarcalismo y en el androcentrismo, lo cual provoca que mujeres y hombres no cuenten con las mismas oportunidades.

En materia del espacio de participación político-electoral, el establecimiento de "reglas neutrales" ha conducido a resultados desiguales, fortaleciendo la idea y el hecho de que la política es "cosa de hombres". De ahí la necesidad de establecer acciones afirmativas en beneficio de la participación política de las mujeres, una de las primeras medidas fueron las cuotas de género ${ }^{4}$, que tenían un doble propósito, el primero garantizar que más mujeres tuvieran espacio en las candidaturas; y el segundo que cada vez más mujeres ocuparan puestos de toma de decisiones.

Sin embargo, veremos que esta medida también encontraría limitaciones, debido a que por un lado, las cuotas de género plantean un umbral mínimo de candidatas mujeres para ser postuladas a los parlamentos, en la mayoría de países el rango se estableció entre los 20\% a 40\%, aplicándose más como un requisito a cumplir que como un verdadero compromiso de las organizaciones políticas porque cada vez más mujeres fueran candidatas con

4 Las cuotas de género tienen como objetivo la construcción de un nuevo modelo de ciudadanía en un sentido amplio de espacio público en el que se atiendan de manera eficaz los desafíos actuales en torno a la ciudadanía de las mujeres en temas como la representación, la gobernabilidad, la delegación de poder y las formas de liderazgo (CEPAL, 2007). Encontramos tres tipos de cuotas de género: 1) Por la vía constitucional; 2) Por la vía legislativa en las leyes electorales, a través de las candidaturas; y, 3) Por la vía de los partidos políticos para cargos internos. 
oportunidades de ocupar una dignidad pública. Por otro, encontramos casos respecto de la simulación para el cumplimiento de esta ley, en la que los partidos políticos obligaban a sus candidatas electas a renunciar para dejar el cargo a un hombre, evadiendo en la práctica esta acción afirmativa a favor de las mujeres.

A partir de la aplicación de las cuotas de género surgen los cuestionamientos respecto del verdadero avance cuantitativo de mujeres en las candidaturas, sobre todo si consideramos que en la mayoría de los países se aplicaron los mínimos en las cuotas, porcentaje que no se reflejó en la posición de mujeres en cargos públicos, asumiendo esta medida más como una cuota a cubrir o como un techo, y no como la base para proyectar más espacios para las mujeres. En este sentido, el otro cuestionamiento se da respecto del avance cualitativo que invita a analizar y reflexionar la profundización de los procesos democráticos en el ámbito de la política, en donde se generen espacios y oportunidades para la participación política de las mujeres no sólo para el ingreso a la política, sino sobre todo para su permanencia y oportunidad para incidir en la agenda pública.

En oposición a la aplicación de las cuotas de género que fue visto como un techo para la generación de espacios de participación política de las mujeres, se plantea el establecimiento de la paridad que permita la total integración de los espacios de representación en igualdad para mujeres y hombres, esto quedó definido en la Conferencia de Atenas desarrollada en 1992. La base para este planteamiento en un principio fue numérica, al señalar que si la mitad de la población y de la ciudadanía está conformada por mujeres correspondía de igual forma la necesidad de que al menos la mitad de la representación también descansara en las mujeres.

Es importante nuevamente hacer notar que si bien resulta un paso fundamental la cuestión cuantitativa en la participación política de las mujeres, el cambio profundo hacia una democracia sustantiva tendrá que pasar también 
por lo cualitativo, es decir, es necesario seguir generando espacios para que la presencia de más mujeres en colaboración con los hombres transformen las formas de hacer política y así construir una nueva cultura política. En este sentido, vemos que en el Consenso de Quito de 2007 se estableció para América Latina que "la paridad es uno de los propulsores determinantes de la democracia, cuyo fin es alcanzar la igualdad en el ejercicio del poder, en la toma de decisiones, en los mecanismos de participación y representación social y política, y en las relaciones familiares al interior de los diversos tipos de familias, las relaciones sociales, económicas, políticas y culturales, y que constituye una meta para erradicar la exclusión estructural de las mujeres" (CEPAL, 2007: 3).

No obstante, los avances registrados en materia de generación de espacios de participación política para las mujeres, aún sigue persistiendo resistencia al pleno ejercicio de los derechos político-electorales de las mujeres. Es por ello, que resulta trascendental seguir generando acciones que tiendan a modificar las estructuras patriarcales y androcéntricas en las que se basa la representación política de la mayoría de nuestras democracias, así como las prácticas políticas en las que predominan estereotipos machistas que obligan a las mujeres a masculinizarse para entrar y permanecer en política, de ahí que también se debe analizar el rol y la función de las mujeres en los espacios de toma de decisión. 


\section{El sistema electoral mexicano}

El gobierno de México está constituido como una República representativa, democrática, laica y federal (Art. 40 Constitución), la condición de federación implica que en cada uno de los 32 estados $^{5}$ que integran el país cuenta con una constitución local, que sin contravenir la carta magna nacional o el Pacto Federal, regula y establece normativa para atender a las particularidades de cada región. La soberanía del pueblo se ejerce a través de los Poderes de la Unión: Ejecutivo, Legislativo y Judicial.

El sistema electoral mexicano siguiendo el marco constitucional se construye para la elección de representantes en dos de las funciones del Estado, el Ejecutivo y el Legislativo, tanto a nivel nacional como local. A nivel nacional se elige presidente/a de la República en elección directa por mayoría relativa, por lo que no se contempla la segunda vuelta, la duración del mandato es de seis años sin posibilidad de reelección. En lo que respecta al legislativo, éste se conforma por dos cámaras: la de Diputados o Cámara Baja y la de Senadores o Cámara Alta cuya integración se detalla en el cuadro que sigue:

5 Aguascalientes, Baja California, Baja California Sur, Campeche, Coahuila de Zaragoza, Colima, Chiapas, Chihuahua, Durango, Guanajuato, Guerrero, Hidalgo, Jalisco, México, Michoacán, Morelos, Nayarit, Nuevo León, Oaxaca, Puebla, Querétaro, Quintana Roo, San Luis Potosí, Sinaloa, Sonora, Tabasco, Tamaulipas, Tlaxcala, Veracruz, Yucatán, Zacatecas y el Distrito Federal. 


\section{Tabla 2.}

Conformación del Congreso de la Unión en México

\begin{tabular}{|c|c|}
\hline \multicolumn{2}{|c|}{$\begin{array}{c}\text { Congreso de la Unión } \\
\text { (Artículos } 50 \text { a } 70 \text { de la Constitución) }\end{array}$} \\
\hline CÁMARA DE DIPUTADOS & CÁMARA DE SENADORES \\
\hline 500 miembros & 128 miembros \\
\hline $\begin{array}{c}300 \text { elegidos por el principio } \\
\text { de mayoría relativa en distritos } \\
\text { uninominales }\end{array}$ & $\begin{array}{l}64 \text { se eligen por el principio de mayoría } \\
\text { relativa (una fórmula de } 2 \text { candidatos } \\
\text { por cada entidad federativa) }\end{array}$ \\
\hline $\begin{array}{c}200 \text { elegidos por el principio } \\
\text { de representación proporcional } \\
\text { en circunscripciones plurinom- } \\
\text { inales }\end{array}$ & $\begin{array}{l}32 \text { asignados a la primera minoría (1 } \\
\text { para el partido que obtuvo el segundo } \\
\text { lugar en la elección de cada entidad) }\end{array}$ \\
\hline Se renueva cada 3 años & $\begin{array}{l}32 \text { elegidos por el principio de repre- } \\
\text { sentación proporcional }\end{array}$ \\
\hline $\begin{array}{c}\text { Se permite la reelección por } \\
\text { tres periodos consecutivos para } \\
\text { permanecer en la cámara hasta } \\
\text { por } 12 \text { años }\end{array}$ & $\begin{array}{l}\text { Se renueva cada } 6 \text { años y se permite la } \\
\text { reelección por un periodo para perman- } \\
\text { ecer en la cámara hasta por } 12 \text { años }\end{array}$ \\
\hline
\end{tabular}

Fuente: Constitución Política de los Estados Unidos Mexicanos. Elaborado por: Autora.

En lo que respecta al poder ejecutivo local se elige al gobernador/a en elección directa por mayoría relativa y la duración del mandato es de seis años sin posibilidad de reelección. Mientras que el poder legislativo se conforma por una sola cámara la de diputados, el número de legisladores varía en cada una de las 32 entidades federativas y se determina de acuerdo a la cantidad de la población, extensión geográfica y a los usos y costumbres de algunas zonas con pueblos y comunidades indígenas. De igual forma, varía el número de autoridades municipales que se eligen en cada Estado. En el 
caso de la legislación local se permite la reelección hasta por cuatro periodos consecutivos para permanecer hasta 12 años, mientras que en el caso de las alcaldías municipales la reelección es sólo por un periodo, es decir, la autoridad electa puede permanecer hasta 6 años.

La estructura electoral mencionada anteriormente es producto de un proceso de transición a la democracia ${ }^{6}$ que además de ir acompañada de cambios a las normas generales del país en áreas económicas, sociales, de derechos humanos, entre otras, se concentró de manera fundamental en la modificación de las normas e instituciones electorales teniendo como uno de los principales objetivos permitir que la integración de los órganos de representación política fueran el reflejo de la diversidad no sólo política sino social que conforma al país.

El proceso de cambio político electoral en México, tanto durante la transición a la democracia como en el proceso que vino después y que ha sido denominado de consolidación democrática se ha articulado a través de ocho reformas electorales federales, las cuales han buscado que la representación política se construya a partir del reflejo de los diversos sectores que conforman el país, en este constante anhelo es que se han producido estos cambios a la normativa electoral, y que de manera fundamental han rediseñado de manera constante las instituciones encargadas de organizar y calificar las elecciones para garantizar la calidad democrática en el país. Las reformas a las que nos referimos se llevaron a cabo en: 1977, 1986, 1989-1990, 1993, 1994, 1996, 2007 y $2014^{7}$.

6 Sobre el tema de la transición a la democracia en México pueden referirse a los siguientes autores: Becerra (2000); Elizondo y Nacif (2002); Aziz (2003); Merino (2003), entre otros.

7 Sobre las reformas electorales en México: Becerra (2000), Cansino (2000), Eisenstadt (2004), entre otros. 


\section{Reforma a las leyes electorales en el ámbito nacional}

Como se mencionó anteriormente el proceso de reformas político-electorales fue dando respuesta tanto a la propia dinámica del sistema electoral y sus diversos actores -organismos electorales y partidos políticos- pero sobre todo atendió demandas de la sociedad que de a poco se iba apropiando de los espacios de participación democrática. Ejemplo de ello fue la movilización de grupos de mujeres que desde la sociedad civil y al interior de los partidos políticos impulsaron la primera reforma federal electoral que permitiera garantizar la participación política de las mujeres.

Los derechos políticos de las mujeres en México se remontan a 1953 año en el que se aprobó el derecho de voto de las mujeres, que cabe destacar no fue una concesión del entonces presidente Adolfo Ruiz Cortines sino la conquista ganada por la Alianza de Mujeres de México encabezada por Adelina Zendejas y Esther Chapa, quienes lograron juntar las 500 mil firmas que les solicitaron para aprobar el sufragio femenino (Bartra, 2002: 72) y en consecuencia el reconocimiento pleno de la ciudadanía de las mujeres que trajo consigo la reforma en 1954 a la Ley Electoral para reconocer a las mujeres plenos derechos políticos, esto es, elegir y ser elegidas ${ }^{8}$.

Luego de cuarenta años de haberse reconocido los derechos políticos a las mujeres tanto en la Constitución como en la Ley Electoral, en 1993 se aprobó en el Código Federal de Instituciones y Procedimientos Electorales (COFIPE) una reforma que invitaba a los partidos políticos la promoción, en los términos que establecieran sus documentos internos, una mayor participación de las mujeres en la vida política del país, mediante su

8 El nuevo texto constitucional en el artículo 34 señalaba: Son ciudadanos de la República los varones y mujeres que, teniendo la calidad de mexicanos, reúnan, además los siguientes requisitos: haber cumplido 18 años, siendo casados, o 21 si no lo son, y tener un modo honesto de vivir. Actualmente en el mismo artículo se ha eliminado el estatus de casado/a que sin duda restringía el pleno ejercicio de derechos político-electorales. 
postulación a cargos de elección popular (art. 173, fracción III), de ninguna forma se obligaba y garantizaba que actuaran en consecuencia.

La ausencia de medidas que obligaran a los partidos políticos a garantizar la presencia de las mujeres tanto en su vida interna como en la postulación de candidaturas prevaleció en la reforma al COFIPE de $\mathbf{1 9 9 6}^{9}$, la cual incluyó sólo una recomendación a los partidos políticos nacionales para que consideraran en sus estatutos que las candidaturas a diputados y senadores por ambos principios, no excedieran el $70 \%$ para un mismo género.

Ante la ausencia de una norma que garantizara la presencia de mujeres en las postulaciones de los partidos y nuevamente ante la presión tanto de organizaciones de mujeres de la sociedad civil como al interior de los partidos, finalmente en el $\mathbf{2 0 0 2}$ se aprobó la primera Ley de Cuotas de Género que reformaba el COFIPE, estableciendo la obligación a los partidos políticos de promover la igualdad de oportunidades y la equidad entre hombres y mujeres a través de postulaciones a cargos de elección popular en el Congreso de la Unión.

Esta Ley de Cuotas recuperaba de la reforma de 1996 el porcentaje mínimo en el que se debían considerar las candidaturas para las mujeres, correspondiente al $30 \%$, esto es, los partidos no podían rebasar el $70 \%$ de registros de candidatos propietarios de un mismo género (Art. 175-A). La norma sancionaba con el rechazo del registro de candidaturas si no se presentaban bajo este criterio, con un plazo de 48 horas como máximo para hacerlo correctamente. Las listas de representación proporcional se integraban por segmentos de tres candidaturas. En cada uno de los tres primeros segmentos de cada lista se colocaba una candidatura de género distinto, de no cumplirse los partidos políticos podrían ser sancionados con amonestación pública o con la negativa del registro de candidaturas (Art. 175-B).

9 Artículo transitorio vigésimo segundo del Decreto de reforma al COFIPE 1996. 
Sin embargo, la norma encontraba su excepción en las candidaturas de mayoría relativa ya que estas sanciones no procedían si la definición de las mismas había sido resultado de un proceso de elección de voto directo. Esto sin duda, afectó de manera importante los alcances, la eficacia y los resultados de las candidaturas de mujeres por el principio de mayoría relativa, y en consecuencia disminuía las posibilidades de que alcanzaran algún puesto en el Congreso.

La reforma al COFIPE de los años 2007-2008 modificó el porcentaje de la cuota de género en la postulación de candidaturas, estableciendo en $40 \%$ la cuota mínima de candidatos/as propietarios/as de un mismo género. Asimismo estableció que las listas plurinominales debían incluir al menos dos mujeres en cada segmento de cinco candidatos. Las candidaturas de mayoría relativa se mantuvieron exentas de cubrir cuotas de género siempre y cuando fueran resultado de un proceso de elección democrática, conforme a los estatutos de cada partido. La reforma añadió, en el artículo 78 del COFIPE, la indicación para que todos los partidos destinaran, al menos, el $2 \%$ del gasto ordinario en actividades para la capacitación y formación del liderazgo político de las mujeres (Arts. 219 y 220).

No obstante, encontramos que los partidos políticos evadieron la norma encontrando recursos para no aplicar la cuota en su totalidad o en algunos casos la cumplían de manera simulada, esto se reflejó con el caso denominado "Las Juanitas" que consistía en postular a mujeres tanto en las candidaturas de mayoría relativa como proporcional y una vez que asumían el cargo éstas renunciaban para dejar en su cargo a un hombre. Cabe señalar, que los motivos de las renuncias eran diversos: por acuerdos internos, por presiones en contra de las mujeres ya sea por tratarse de algún familiar, y en los casos más extremos se empezaban a registrar casos de violencia que iban de lo psicológico a lo físico, evidenciando la ausencia de normativa que atendiera en concreto este tipo de violencia política contra las mujeres. 
Luego de registrarse y denunciarse varios casos de Juanitas, el Consejo General del Instituto Federal Electoral, en vísperas de la elección de 2012, estableció en el Acuerdo CG327/2011, que ningún partido político o coalición incluiría más de $60 \%$ de candidatos propietarios a diputados y senadores de un mismo género del total de las solicitudes de registro de candidaturas, tanto de mayoría relativa como de representación proporcional.

Este acuerdo provocó una serie de impugnaciones por parte de los partidos políticos, lo que llevó el caso al Tribunal Electoral del Poder Judicial de la Federación (TRIFE), mismo que emitió la sentencia, identificada con el expediente SUP JDC 12624/2011 y acumulados, que puede calificarse como la más importante en términos de igualdad de género en el México contemporáneo. Entre las disposiciones centrales de dicha resolución destacan las siguientes:

- Que los partidos políticos deberán presentar como mínimo 120 candidatos a diputados y 26 candidatos a senadores propietarios de un mismo género, en el caso de legisladores de mayoría relativa.

- Que de la totalidad de las solicitudes de registro, por ambos principios (mayoría relativa y representación proporcional) tanto de diputados como de senadores, al menos $40 \%$ de las candidaturas deben integrar fórmulas completas (propietario y suplente) de un mismo género.

Esto sin duda tuvo un impacto no sólo en el número de mujeres que fueron postuladas, sin embargo, no hubo el mismo efecto en la conformación de las legislaturas en donde seguía prevaleciendo una mayor cantidad de hombres en los congresos. Además del efecto cuantitativo debe tomarse en cuenta la resistencia que prevaleció en las formas de hacer política, pues se seguía considerando el espacio de la política como algo exclusivo de los hombres, si 
bien para esta elección sólo se tuvo registro oficial de dos casos de denuncia de violencia política de género, eso no significaba que no existieran más hechos que violentaban no sólo el acceso de mujeres a la política sino su permanencia, tema que abordaremos más adelante.

Finalmente, y a pesar de la resistencia de las cúpulas de los partidos políticos se aprobó en el 2014 una nueva reforma político-electoral que dejaba atrás la Ley de Cuotas para dar paso a la Ley de Paridad. La relevancia de esta reforma radicó en el hecho de no centrarse sólo a la Ley Electoral, sino que fue promovida desde el rango constitucional obligando a los partidos políticos a garantizar la paridad de género en las candidaturas tanto para las legislaturas nacionales como estatales.

El artículo 41 de la Constitución Política de los Estados Unidos Mexicanos mandata que la totalidad de solicitudes de registro, tanto de las candidaturas a diputados/as como de senadores/as que presenten los partidos políticos o las coaliciones ante el ahora Instituto Nacional Electoral (INE), deberán integrarse salvaguardando la paridad entre los géneros. Esta reforma político-electoral dio paso a la nueva Ley General de Instituciones y Procedimientos Electorales (LGIPE) antes COFIPE en la que también se recogió el principio de paridad (Arts. 7, 232, 233, 234 y 241). ${ }^{10}$

LGIPE Arts. 232-233: las listas de representación proporcional, se integrarán por fórmulas de candidatos en las que tanto propietario como suplente deben ser del mismo género, y se alternarán fórmulas de distinto género hasta agotar cada lista.

10 La reforma político electoral del 2014 también modificó la Ley General de Partidos Políticos en el artículo 4 numeral 4: cada partido político determinará y hará públicos los criterios para garantizar la paridad de género en las candidaturas a legisladores/as. También se modifican los artículos 25 y 73. 
En el registro de candidaturas de mayoría relativa, la totalidad del registro de diputaciones como de senadurías se integrarán con un 50\% de candidatas/os propietarias/os y suplentes de un mismo género y el 50\% restante del género opuesto. Para la representación proporcional, se integrarán por segmentos de cinco las fórmulas de candidatas/os, en cada uno de los segmentos, que se establecerán de forma alternada con las fórmulas de género distinto, hasta agotar cada lista.

Podemos ver que el principio de paridad viene acompañado de las nociones de secuencialidad y alternabilidad. En primer lugar porque la presentación de las candidaturas se van alternando ya sea hombre-mujer-hombre o mujer-hombre-mujer, según sea el caso, y asimismo se va respetando la secuencialidad sin que haya dos mujeres o dos hombres seguidos. También debemos resaltar que al establecer que las candidaturas presentadas sean de un mismo género se garantiza que ante la necesidad de hacer efectiva la suplencia ésta será del mismo género que la principal, con lo cual se está evitando el fenómeno de las Juanitas.

\section{Reformas a las leyes electorales en el ámbito local}

La condición de República federal permite que en el ámbito de las entidades federativas se genere diferencias en materia de legislación electoral, nuevamente reiterando que estas particularidades no pueden estar fuera de la norma constitucional nacional. Sin embargo, en materia de cuotas de género si encontramos diferencias entre cada Estado, producto también de la variación numérica en la conformación de cada legislatura local.

En este contexto, las reformas político-electorales realizadas a nivel nacional de a poco fueron teniendo impacto en las legislaciones electorales locales que debieron adaptar y armonizar la normativa local en materia de cuotas 
de género. Lo que encontramos es que en algunas entidades se plantean sólo a manera de recomendación/indicación, mientras que en otras se contemplan estipulaciones precisas respecto a la observancia de la obligatoriedad, incluyendo sanciones (Medina, 2010: 58). Esta diferenciación en la norma electoral también se refleja en el tipo de candidatura en la que cada entidad federativa aplica la Ley de Cuotas, ya sea por mayoría relativa o representación proporcional, así como en el porcentaje contemplado para la cuota.

\section{Tabla 3.}

Cuotas de género a nivel local

\begin{tabular}{|c|c|c|c|c|}
\hline \multicolumn{5}{|c|}{ CUOTAS DE GÉNERO EN 25 ENTIDADES FEDERATIVAS AL 2009} \\
\hline $\begin{array}{c}\text { Paridad } / \\
\mathbf{5 0 \%}\end{array}$ & $40 \%$ & $30-25 \%$ & Mixto & $\underset{\text { definir** }}{\text { Sin }}$ \\
\hline 4 & 6 & 12 & 1 & 2 \\
\hline $\begin{array}{c}\text { Campeche, } \\
\text { Chihuahua, } \\
\text { Guerrero y } \\
\text { Sonora }\end{array}$ & $\begin{array}{l}\text { Aguascalien- } \\
\text { tes, Coahuila, } \\
\text { Distrito Fede } \\
\text { ral, Oaxaca, } \\
\text { Querétaro y } \\
\text { Tamaulipas }\end{array}$ & $\begin{array}{l}\text { Baja California } \\
\text { Sur, Duran- } \\
\text { go, Estado } \\
\text { de México, } \\
\text { Jalisco, Micho- } \\
\text { acán, Morelos, } \\
\text { Puebla*, San } \\
\text { Luis Potosí, } \\
\text { Sinaloa, Vera- } \\
\text { cruz, Yucatán y } \\
\text { Zacatecas }\end{array}$ & Colima & $\begin{array}{c}\text { Guanajuato } \\
\text { y Nayarit }\end{array}$ \\
\hline
\end{tabular}

Fuente: Centro de Estudios para el Adelanto de las Mujeres y la Equidad de Género (CEAMEG), en Medina, 2010: 59-61.

Elaborado por: Autora.

*Correspondía el $25 \%$ la cuota de género.

** Para el caso de Guanajuato la ley determinaba incluir en los tres primeros lugares de cada lista a varones y mujeres. Mientras que en caso de Nayarit señalaba "procurar la equidad de género".

Faltan los estados de: Baja California, Chiapas, Hidalgo, Nuevo León, Quintana Roo, Tabasco y Tlaxcala. 
De acuerdo con el cuadro anterior en la mayoría de los estados prevaleció hasta el 2009 el $30 \%$ para la ley de cuotas, asimismo destaca que sin estar determinado en la ley electoral nacional cuatro entidades federativas ya favorecían el principio de paridad, permitiendo sentar un buen precedente a ser retomado en la legislación nacional.

Finalmente, hay que destacar que la reforma político-electoral de 2014 al tener rango constitucional generó un impacto automático en todas las legislaciones locales, obligándolas a adoptar el principio de paridad sin distinción, lo que sin duda tuvo repercusiones no sólo en la norma sino en las formas de hacer política que en estados de arraigo político tradicional iba a generar un impacto negativo reflejado en más casos de violencia política en contra de las mujeres, que de acuerdo con el TRIFE para el proceso electoral local de 2014-2105 se registraron al menos 38 denuncias de este tipo, mientras que en 2012 sólo se habían hecho dos denuncias.

\section{Análisis de los resultados electorales nacionales: Cámara de Diputados y de Senadores}

Como se mencionó en el primer apartado el Poder Legislativo mexicano es bicameral, y es considerado uno de los más numerosos en el continente, pues en total suma 628 legisladores/as (500-Cámara de Diputados y 128-Cámara de Senadores). El sistema electoral es mixto ya que combina el principio de mayoría relativa con el de representación proporcional, entre las razones de este diseño se encuentran, dar la oportunidad a la generación y consolidación de nuevas fuerzas políticas.

Este diseño electoral ha generado un impacto en el sistema de partidos mexicanos, que por más de 70 años se había constituido como de partido hegemónico ${ }^{11}$, siendo el Partido Revolucionario Institucional (PRI) el 11 De acuerdo con Giovanni Sartori y su propuesta de tipología de sistemas de par- 
protagonista al ocupar la presidencia por este periodo de manera ininterrumpida, controlando la mayoría en el legislativo nacional en ambas cámaras, así como los gobiernos locales y sus respectivos congresos y municipios.

Actualmente, y siguiendo a Sartori, podemos considerar el sistema de partidos mexicano de tipo multipartidista moderado ${ }^{12}$, debido a que son tres los partidos importantes: PRI, PAN y PRD. Esto tomando en cuenta no sólo su fuerza electoral, al obtener escaños por más de tres periodos consecutivos en el legislativo, sino también por su capacidad de coalición en el congreso, esto quiere decir, que no hay una fuerza política que controle o tenga mayoría absoluta en el legislativo por lo que requieren establecer alianzas para la aprobación de leyes. Además porque existen posibilidades reales de alternancia entre estas fuerzas políticas, esto se evidenció cuando el otrora partido oficial -el PRI- perdió la presidencia de la República en el 2000 frente al PAN quien gobernó por dos periodos consecutivos, o en la elección del 2006 entre el PAN y el PRD al disputarse la presidencia, definiéndose con un margen muy estrecho y mostrando un alto nivel de competitividad que no se había registrado anteriormente en el sistema político mexicano.

Asimismo el diseño electoral mexicano, permite la presencia de

tidos, un sistema de partido hegemónico es: aquel que dentro un marco democrático, permite la existencia de otros partidos pero no permite la competencia política para el ejercicio del poder; un partido político tiene el monopolio del poder político; los partidos periféricos o satélites sirven para dar una imagen de pluralismo político, pero la igualdad es en realidad inexistente, puesto que no se dan posibilidades de alternancia o rotación en el poder; el partido hegemónico tiene la voluntad de cooptar a aquellos pequeños partidos con más fuerza potencialmente y si ello no es posible los reprime o limita. (Sartori, 2002)

12 Según Sartori el sistema de partidos de pluralismo limitado o moderado se caracteriza porque: el número de partidos importantes oscila aproximadamente, de tres a cinco; los gobiernos acostumbran a ser de coalición puesto que ninguno de los partidos consigue los escaños necesarios para tener la mayoría absoluta; pueden darse los gobiernos de un solo partido, que acostumbran a ser débiles y poco estables; también se produce una competencia electoral centrípeta -tienden al centro y la distancia ideológica es estrecha-; existe una oposición unilateral y no hay partidos antisistema importantes. (Sartori, 2002) 
otros partidos políticos que si bien no son altamente competitivos o con posibilidades de alternancia, si juegan un papel importante respecto de su capacidad de chantaje, esto quiere decir, que pueden representar una opción para los partidos mayoritarios en la conformación de alianzas. En el escenario de partidos mexicano se pueden considerar tres que cumplen esta función: PVEM, PT y Movimiento Ciudadano, quienes en los últimos años han consolidado alianzas tanto políticas como electorales. Por un lado, tenemos la alianza entre el PRI y el PVEM quienes han ido juntos tanto para elecciones nacionales como locales. Por otro, está la alianza denominada de la "izquierda mexicana" conformada por el PRD, PT y Movimiento Ciudadano, también en el ámbito nacional y local. Finalmente, encontramos que en los últimos años han surgido nuevas fuerzas políticas que de a poco han consolidado su presencia, esto son: PANAL y MORENA, los cuales han permanecido constantes en sus niveles de votación.

Sibien el sistema político mexicano, incluyendo al sistema de partidos y al electoral, puede considerarse en el marco de un sistema democrático, aún restan algunos pendientes para hablar de un proceso consolidado y de calidad, esto debido a que si bien se ha establecido una "regularidad" electoral, con procesos ininterrumpidos, alternancia política y reformas electorales que han atendido a las nuevas demandas de la ciudadanía. Aún prevalecen elementos que denotan una brecha entre representantes-representados, esto se refleja en la alta desconfianza de los ciudadanos hacia los partidos políticos, a lo que se suman otros factores como el económico, de inseguridad por la delincuencia común y el narcotráfico, y las constantes denuncias de corrupción, entre otros.

En este escenario, cobra relevancia la lucha que desde los grupos organizados de mujeres consiguieron en primer lugar el derecho al voto, para posteriormente y de a poco ir ganando lugares en los espacios de decisión pública. Al igual que como se señaló en el apartado anterior, el camino ha sido largo y lento, pues como veremos a continuación una vez que fueron 
promovidas las leyes que favorecen la participación política de las mujeres, los efectos no han sido inmediatos y han encontrado nuevos obstáculos. Sin embargo, también encontramos que la presencia política de las mujeres se ha sostenido especialmente a nivel nacional, por lo que resta vigilar el proceso político electoral para replicar los efectos positivos a nivel local.

\section{Participación política de las mujeres en la Cámara de Diputados}

En el siguiente gráfico se observa la evolución de la participación política de las mujeres en la Cámara de Diputados en el periodo que va de 1952 a 2018. Podemos ver que desde que se garantizaron los derechos políticos de las mujeres en 1953 hasta la primera recomendación hecha por el organismo electoral para incluir a las mujeres en las listas de candidaturas a las diputaciones en 1993, existe un marcado predominio de los hombres. Sin embargo, se registra un aumento de poco más de cinco puntos porcentuales que incrementó la presencia de las mujeres en esta cámara para el periodo 1994-1997.

Aunque el número de mujeres en las diputaciones seguía siendo bajo, este aumento favoreció la siguiente propuesta del instituto electoral hecha en 1996 en la que se recomendaba a los partidos políticos no presentar listas que rebasaran en más de un 70\% la postulación de un mismo género, que si bien no los obligaba permitió otro aumento de tres puntos porcentuales de escaños para mujeres en la legislatura 1997-2000. No obstante, para el siguiente periodo 2000-2003, vemos un descenso de un punto porcentual, que sin duda abrió paso para que el instituto electoral pasara de las recomendaciones a las normas que mandataran a los partidos políticos mayores espacios para las mujeres en las candidaturas.

Luego de que en 2002 se aprobara la primera Ley de Cuotas en México, en la que se estableció como mínimo un 30\% de candidaturas para mujeres, se registró un impacto positivo en la conformación de la legislatura 
para el periodo 2003-2006, al incrementarse en más de 8 puntos porcentuales el número de escaños para mujeres. Sin embargo, para el siguiente periodo legislativo 2006-2009, se observa un retroceso de poco más de $2 \%$ que ponía en duda la efectividad de la Ley de Cuotas, o de manera específica de su efecto en la conformación de las cámaras con mayor presencia de mujeres.

\section{Gráfico 1.}

Porcentaje de diputadas y diputados federales por Legislatura, 1952 - 2018

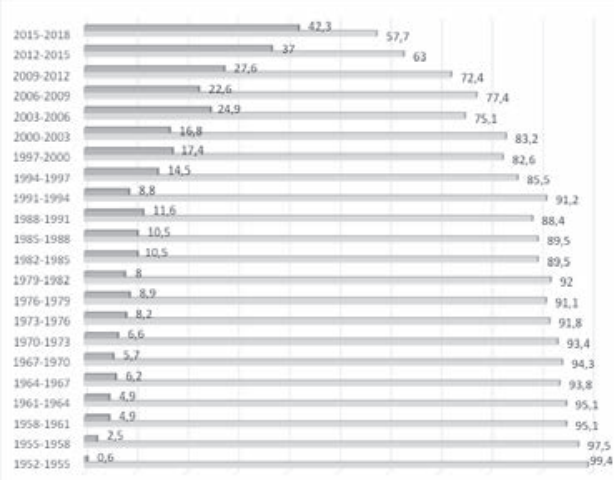

Fuente: www.diputados.gob.mx

Elaborado por: Autora.

Es por ello, que en la reforma electoral del 2007-2008 se dispuso la modificación a la Ley de Cuotas estipulando como mínimo 40\% de candidaturas para mujeres, con esto se registró nuevamente un impacto que favoreció la presencia de mujeres diputadas, al incrementarse en cinco puntos porcentuales el número de escaños para el periodo 2009-2012. Esta tendencia a la alza no sólo se iba a refrendar en el siguiente periodo legislativo 2012- 
2015, sino que alcanzaría el mayor incremento en la participación política de las mujeres en la cámara de diputados, del que se tiene registro hasta la fecha, aumentando en diez puntos porcentuales.

Este escenario dio paso a la reforma constitucional más reciente que estableció la Ley de Paridad en la presentación de candidaturas tanto en el legislativo nacional -Diputados y Senadores- estableciendo reglas para el cumplimiento de esta norma en los dos principios de representación (mayoría relativa y proporcional), así como aplicar la paridad a nivel estatal. Resultado de esta ley se registró un incremento de cinco puntos porcentuales para el periodo 2015-2018, lo que implicó un aumento de 26 diputadas más en la cámara respecto de la legislación anterior, para sumar un total de 211 .

\section{Gráfico 2.}

Cámara de Diputados. Número de escaños por género 1991-2018

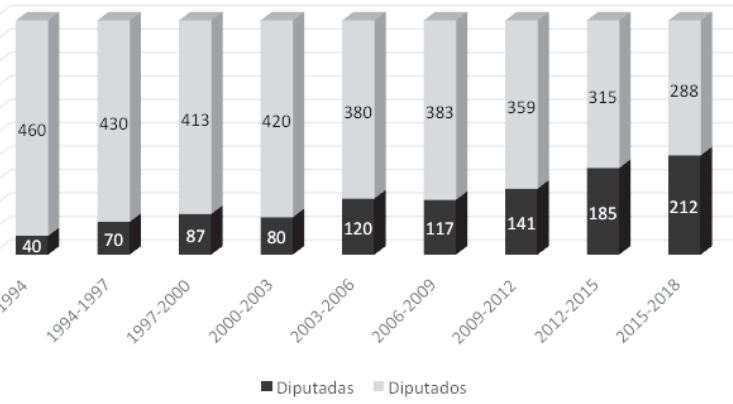

Fuente: www.diputados.gob.mx y www.ine.mx Elaborado por: Autora. 
Esta tendencia a la alza se ha mantenido desde el 2009, si bien aún no se logra la paridad en la conformación de la cámara, el margen para conseguirlo es de apenas 8 puntos porcentuales. En este sentido, habrá que esperar a la siguiente elección en 2018, en donde además de contar con la Ley de Paridad en un segundo proceso electoral, se tiene la posibilidad de reelección, que antes estaba prohibida. Por lo que será interesante analizar cuántas de las mujeres que ya ocupan un escaño se mantienen y si estos dos elementos conjugados permiten incrementar el número de diputadas y así alcanzar la paridad.

En el siguiente gráfico podemos ver cómo el impacto de la reciente reforma, en la que se obliga a los partidos políticos a presentar sus listas de mayoría relativa respetando el principio de paridad, tuvo un efecto positivo, pues anteriormente había sido el espacio con menos escaños para mujeres, de lo cual podemos aducir que ante la presentación de más candidaturas de mujeres por la vía de elección directa, se muestra una tendencia favorable a elegirlas. Sin embargo, aún el porcentaje de escaños por esta vía para las mujeres no llega a la mitad, por lo que ahora resta analizar las condiciones en las que las mujeres participan y pueden ser competitivas frente a los candidatos hombres. 


\section{Gráfico 3.}

Número de Diputadas según tipo de representación 2009-2018

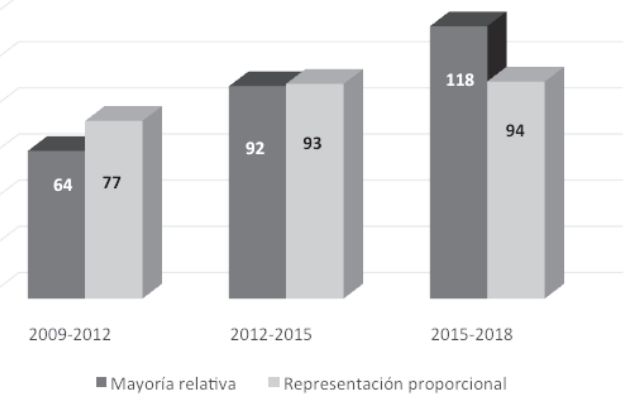

Fuente: www.diputados.gob.mx y www.ine.mx Elaborado por: Autora.

Finalmente, en el siguiente gráfico vemos el número de diputadas por partido, siendo el PRI quien en las tres últimas legislaciones ha mantenido los números más altos, esto también hay que asociarlo con la posición de primera fuerza electoral que ha mantenido en los últimos años. En contraste vemos como la baja en las diputaciones de mujeres, tanto para el PAN como el PRD, se ha asociado a su propio descenso electoral. Destaca en el gráfico, que en la última elección el reciente conformado partido MORENA alcanzó un número mayor de mujeres diputadas incluso frente a partidos de larga data como el PVEM o MOVIMIENTO. Asimismo destaca que en este último periodo legislativo se registran dos diputadas independientes, en este sentido, queda pendiente ver la forma en la que el organismo electoral garantizará la participación de mujeres sin el respaldo partidario, y ver cómo en estos casos que no se aplica la Ley de Paridad, se puede generar alguna normativa que 
garantice la competencia de mujeres por la vía independiente en igualdad de condiciones.

\section{Gráfico 4.}

Número de Diputadas por partido 2009-2018

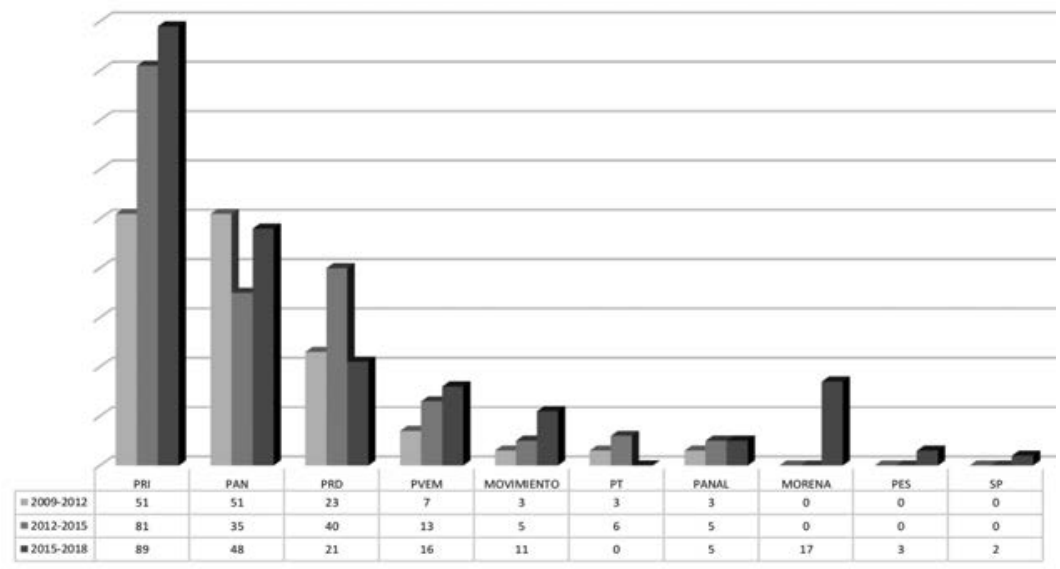

Fuente: www.diputados.gob.mx y www.ine.mx

Elaborado por: Autora.

\section{Participación Política de las mujeres en la Cámara de Senadores}

En el caso del senado mexicano es importante considerar que la evolución respecto de los escaños ocupados por mujeres es más lenta en comparación con la cámara de diputados, esto debido a que, la primera se renueva cada seis años, además es más pequeña por lo que la competencia se intensifica. De acuerdo con el primer gráfico presentado, se observa que en el periodo que va de 1994 al 2018 la presencia masculina es ampliamente mayoritaria. A diferencia de lo observado en la cámara baja, el impacto de las diversas normativas aprobadas para favorecer la presencia de mujeres en esta cámara no ha tenido el efecto 
esperado. En las dos legislaturas que anteceden a la primera Ley de Cuotas (1994-2000 y 2000-2006) las recomendaciones hechas por el organismo electoral para incluir a más mujeres en las listas de candidaturas y que se viera reflejado en la obtención de escaños, es prácticamente simbólica, determinando la Cámara de Senadores como un espacio casi exclusivo de hombres.

\section{Gráfico 5.}

Porcentaje de Senadoras y Senadores, 1994-2018

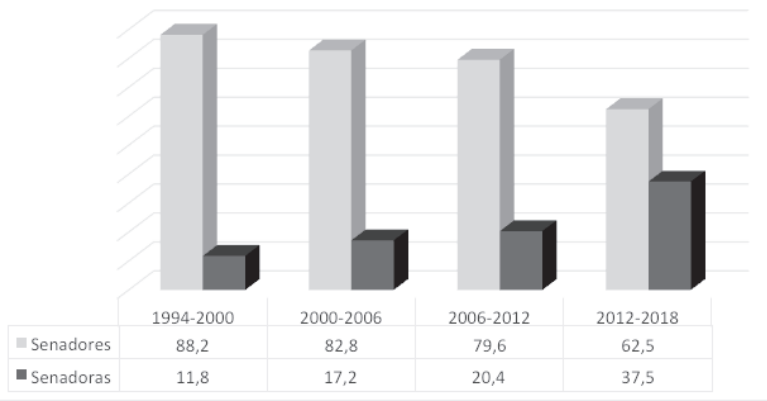

Fuente: www.senado.gob.mx y www.ine.mx Elaborado por: Autora.

Luego de aprobada la primera Ley de Cuotas en el 2002 correspondiente al $70-30 \%$, el incremento en el porcentaje de mujeres apenas fue de tres puntos porcentuales. No obstante, en la siguiente legislatura y ya con una reforma al porcentaje de cuotas establecido en $60-40 \%$ podemos observar un efecto relevante en la presencia de mujeres en esta cámara, con un aumento de más de 17 puntos porcentuales, siendo incluso mayor que el registrado en la cámara de diputados que fue de diez puntos porcentuales. 


\section{Gráfico 6.}

Cámara de Senadores. Número de escaños por género 1994-2018

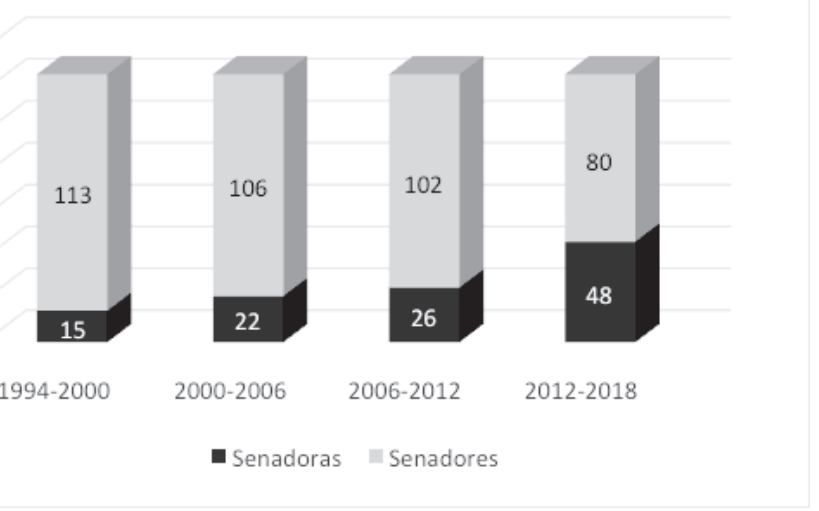

Fuente: www.senado.gob.mx y www.ine.mx Elaborado por: Autora.

Si bien este incremento es significativo aún prevalece una mayoría de hombres en esta cámara, resta esperar el efecto de la Ley de Paridad aprobado en 2014, en la próxima elección para el senado (2018), en la cual también habrá que considerar la influencia de la reelección que se aplicará por primera vez. Asimismo es importante continuar analizando no sólo de manera cuantitativa el efecto de estas leyes, sino las formas de participación y las condiciones de competencia a las que se enfrentan las mujeres, por ejemplo, el número y el tipo de comisiones que presiden dentro de la cámara que pueda evidenciar la capacidad de influencia o no que tengan las mujeres en la toma de decisiones y en la generación de la agenda política que se discute. 


\section{Gráfico 7.}

Número de Senadoras según tipo de representación 2000-2018

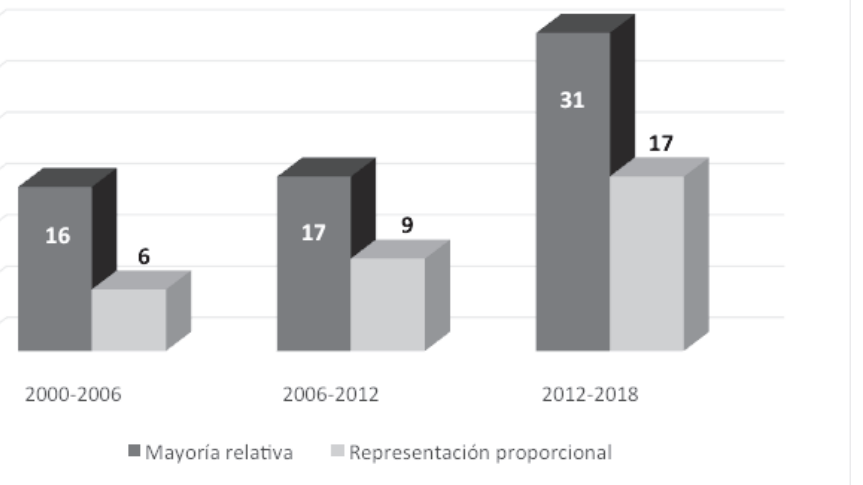

Fuente: www.senado.gob.mx y www.ine.mx Elaborado por: Autora.

A diferencia de lo acontecido en la cámara de diputados, en el senado la presencia de las mujeres respecto del tipo de representación ha sido opuesta, es decir, el mayor número de senadoras se ha registrado por la vía de la mayoría relativa lo que significa que la mayor parte de las mujeres que ocupan un escaño en el senado han sido electas por la ciudadanía, asimismo se observa que las cuotas del partido en la asignación por representación proporcional sigue siendo preferencial para los hombres. Destaca del gráfico anterior que para la elección del 2012, fueron 31 mujeres las que triunfaron en elección directa, por lo que cobra especial atención ver los resultados del proceso que se llevará a cabo en el 2018, cuando se aplique la Ley de Paridad. 


\section{Gráfico 8.}

Número de Senadoras por partido 1994-2018

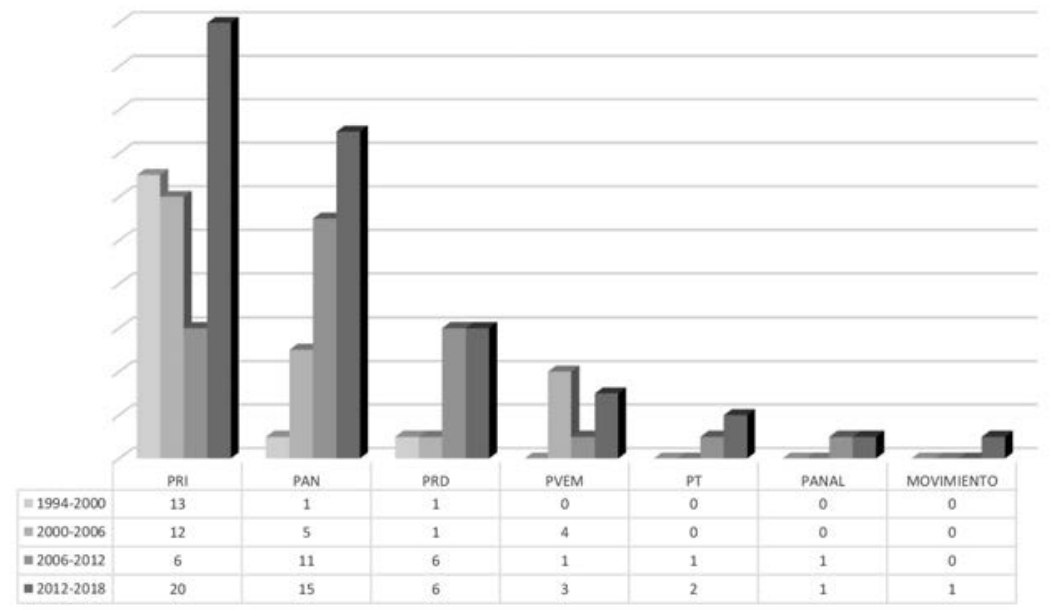

Fuente: www.senado.gob.mx y www.ine.mx Elaborado por: Autora.

En lo que respecta a la determinación de escaños para mujeres por partido político, observamos que al igual que en la cámara de diputados, la mayor cantidad de senadoras registradas han sido por el PRI, siendo el periodo 20062012 el de menor número correspondiendo al momento político-electoral de ese año, cuando los protagonistas de la contienda fueron el PAN y el PRD. Destaca de estos dos últimos partidos que su tendencia de participación de mujeres se ha mantenido estable y a la alza, asimismo para el último periodo legislativo se evidencia no sólo más presencia de senadoras sino mayor diversificación de éstas en las fuerzas políticas, que de confirmarse para la elección de 2018 plantearía un panorama no sólo de equidad sino de mayor pluralidad partidaria en el senado mexicano. 


\section{Análisis de los resultados electorales con la aplicación de la paridad en las elecciones locales de 2015-2016}

En esta sección se analizará el impacto de la Ley de Paridad en los procesos electorales locales inmediatos a su aprobación, es decir, entre el 2015 y 2016. Debido a la extensión que llevaría realizar de manera comparativa la evolución de la aplicación de cuotas a la paridad por Estado, sólo se toman los últimos resultados electorales por cada entidad para la conformación del poder legislativo local. Para un posterior análisis resultaría interesante conocer de manera comparativa cómo ha evolucionado la presencia de las mujeres por Estado, no sólo en el poder legislativo, sino a nivel de las gubernaturas y ayuntamientos, y así poder conocer el impacto tanto de la Ley de Cuotas como la de paridad en todos los niveles de gobierno local.

Análisis del impacto de la Ley de Paridad en la conformación de los legislativos estatales

Lo primero que habría que señalar del calendario electoral en las entidades federativas que conforman la República Mexicana, es que luego del proceso federal del 2014, las elecciones locales se concentraron en dos momentos. El primero corresponde al año 2015, en el que se llevaron a cabo elecciones en 17 Estados, de las cuales sólo en 9 se renovaron de manera simultánea gubernaturas, cámaras legislativas y alcaldías municipales; y en los 8 estados restantes sólo se eligieron a diputados/as y alcaldes/as, el detalle se muestra en el cuadro que sigue: 
Tabla 4.

Calendario electoral procesos locales 2015

\begin{tabular}{|c|c|c|c|c|}
\hline ESTADO & GUBERNATURA & $\begin{array}{l}\text { DIPUTACIONES } \\
\text { DE MAYORÍA } \\
\text { RELATIVA }\end{array}$ & $\begin{array}{c}\text { DIPUTACIONES DE } \\
\text { REPRESEN TACIÓN } \\
\text { PROPORCIONAL }\end{array}$ & $\begin{array}{l}\text { ALCALDÍAS } \\
\text { MUNICIPALES }\end{array}$ \\
\hline $\begin{array}{c}\text { Baja } \\
\text { California } \\
\text { Sur }\end{array}$ & $\mathrm{Si}$ & 16 & 5 & 5 \\
\hline Campeche & $\mathrm{Si}$ & 21 & 14 & 11 \\
\hline Colima & $\mathrm{Si}$ & 16 & 9 & 10 \\
\hline $\begin{array}{l}\text { Distrito } \\
\text { Federal }\end{array}$ & No & 40 & 26 & 16 \\
\hline $\begin{array}{l}\text { Guana- } \\
\text { juato }\end{array}$ & No & 22 & 14 & 46 \\
\hline Guerrero & $\mathrm{Si}$ & 28 & 18 & 81 \\
\hline Jalisco & No & 20 & 19 & 125 \\
\hline México & No & 45 & 30 & 125 \\
\hline Michoacán & $\mathrm{Si}$ & 24 & 16 & 113 \\
\hline Morelos & No & 18 & 12 & 33 \\
\hline $\begin{array}{l}\text { Nuevo } \\
\text { León }\end{array}$ & $\mathrm{Si}$ & 26 & 16 & 51 \\
\hline Querétaro & $\mathrm{Si}$ & 15 & 10 & 18 \\
\hline $\begin{array}{l}\text { San Luis } \\
\text { Potosí }\end{array}$ & $\mathrm{Si}$ & 15 & 12 & 58 \\
\hline Sonora & $\mathrm{Si}$ & 21 & 12 & 72 \\
\hline Tabasco & No & 21 & 14 & 17 \\
\hline Yucatán & No & 15 & 10 & 106 \\
\hline Chiapas & No & 24 & 17 & 122 \\
\hline TOTAL & 9 & 387 & 254 & 1009 \\
\hline
\end{tabular}

Fuente: www.ine.mx

Elaborado por: Autora. 
El segundo momento corresponde a las elecciones locales de 2016, en donde hubo elecciones en 12 estados, de las cuales en 11 se renovaron de manera simultánea gubernaturas, cámaras legislativas y alcaldías municipales. En el estado restante, Baja California, sólo se renovó el poder legislativo y los municipios, como se muestra en el siguiente cuadro:

\section{Tabla 5.}

Calendario electoral procesos locales 2016

\begin{tabular}{ccccc}
\hline ESTADO & GUBERNATURA & $\begin{array}{c}\text { DIPUTACIONES } \\
\text { DE MAYORÍA } \\
\text { RELATIVA }\end{array}$ & $\begin{array}{c}\text { DIPUTACIONES DE } \\
\text { REPRESENTACIÓN } \\
\text { PROPORCIONAL }\end{array}$ & $\begin{array}{c}\text { ALCALDÍAS } \\
\text { MUNICIPALES }\end{array}$ \\
\hline $\begin{array}{c}\text { Aguascali- } \\
\text { entes }\end{array}$ & $\mathrm{Si}$ & 18 & 9 & 11 \\
Baja & $\mathrm{No}$ & 17 & 8 & 5 \\
California & $\mathrm{Si}$ & 22 & 11 & 67 \\
Chihuahua & $\mathrm{Si}$ & 15 & 10 & 39 \\
Durango & $\mathrm{Si}$ & 18 & 12 & 84 \\
Hidalgo & $\mathrm{Si}$ & 25 & 17 & 570 \\
Oaxaca & $\mathrm{Si}$ & 0 & 0 & 0 \\
Puebla & $\mathrm{Si}$ & 15 & 10 & 11 \\
Quintana Roo & $\mathrm{Si}$ & 24 & 16 & 18 \\
Sinaloa & $\mathrm{Si}$ & 22 & 14 & 43 \\
Tamaulipas & $\mathrm{Si}$ & 30 & 20 & 0 \\
Veracruz & $\mathrm{Si}$ & 18 & 12 & 58 \\
Zacatecas & $\mathbf{1 1}$ & $\mathbf{2 2 4}$ & $\mathbf{1 3 9}$ & $\mathbf{9 0 6}$ \\
TOTAL & & & & \\
\hline
\end{tabular}

Fuente: www.ine.mx

Elaborado por: Autora. 
Cabe destacar, que en los estados de Coahuila, Nayarit y Tlaxcala aún no se han realizado elecciones con la Ley de Paridad, sin embargo, para contar con la totalidad de las entidades federativas, se incluyen los datos de la más reciente conformación de sus cámaras legislativas. De acuerdo con el diseño del sistema electoral local, el poder legislativo se conforma bajo dos principios de representación: mayoría relativa y representación proporcional. El total de escaños en las 32 entidades es de 1,466 que dividido en los principios señalados corresponde a 882 de mayoría relativa y a 584 de representación proporcional.

En el siguiente cuadro se observa el total de los escaños en cada entidad por los dos principios de representación y el número correspondiente a las curules ocupadas por mujeres, mostrando un total de 395 diputadas por mayoría relativa y 250 por representación proporcional.

\section{Tabla 6.}

Número de diputadas en Congresos Locales por tipo de representación*

\begin{tabular}{lccccc}
\hline \multicolumn{1}{c}{ ESTADOS } & $\begin{array}{c}\text { Total } \\
\text { escaños } \\
\text { MR }\end{array}$ & $\begin{array}{c}\text { Número de } \\
\text { diputadas } \\
\text { MR }\end{array}$ & $\begin{array}{c}\text { Total } \\
\text { escaños } \\
\text { RP }\end{array}$ & $\begin{array}{c}\text { Número de } \\
\text { diputadas } \\
\text { RP }\end{array}$ & $\begin{array}{c}\text { Total de } \\
\text { diputadas } \\
\text { MR y RP }\end{array}$ \\
\hline AGUAS CALIENTES & 18 & 11 & 9 & 2 & 13 \\
BAJA CALIFORNIA & 17 & 7 & 8 & 2 & 9 \\
BAJA CALIFORNIA & 16 & 7 & 5 & 3 & 10 \\
SUR & 21 & 12 & 14 & 8 & 20 \\
CAMPECHE & 220 & 113 & 162 & 81 & 194 \\
CHIAPAS & 22 & 13 & 11 & 4 & 17 \\
CHIHUAHUA & 16 & 8 & 9 & 4 & 12 \\
COAHUILA & 16 & 5 & 9 & 4 & 9 \\
COLIMA & & & & &
\end{tabular}




\begin{tabular}{|c|c|c|c|c|c|}
\hline $\begin{array}{l}\text { DISTRITO } \\
\text { FEDERAL }\end{array}$ & 40 & 16 & 26 & 14 & 30 \\
\hline DURANGO & 15 & 7 & 10 & 4 & 11 \\
\hline $\begin{array}{l}\text { ESTADO DE } \\
\text { MÉXICO }\end{array}$ & 45 & 19 & 30 & 9 & 28 \\
\hline GUANAJUATO & 22 & 10 & 14 & 6 & 16 \\
\hline GUERRERO & 28 & 11 & 18 & 7 & 18 \\
\hline HIDALGO & 18 & 9 & 12 & 3 & 12 \\
\hline JALISCO & 20 & 8 & 19 & 8 & 16 \\
\hline MICHOACÁN & 24 & 11 & 16 & 6 & 17 \\
\hline MORELOS & 18 & 3 & 12 & 10 & 13 \\
\hline NAYARIT & 18 & 8 & 12 & 6 & 14 \\
\hline NUEVO LEÓN & 26 & 10 & 16 & 6 & 16 \\
\hline OAXACA & 25 & 11 & 17 & 7 & 18 \\
\hline PUEBLA & 26 & 8 & 15 & 4 & 12 \\
\hline QUERÉTARO & 15 & 8 & 10 & 5 & 13 \\
\hline QUINTANA ROO & 15 & 8 & 10 & 3 & 11 \\
\hline SAN LUIS POTOSÍ & 15 & 6 & 12 & 3 & 9 \\
\hline SINALOA & 24 & 12 & 16 & 6 & 18 \\
\hline SONORA & 21 & 9 & 12 & 4 & 13 \\
\hline TABASCO & 21 & 6 & 14 & 7 & 13 \\
\hline TAMAULIPAS & 22 & 9 & 14 & 7 & 16 \\
\hline TLAXCALA & 15 & 4 & 10 & 5 & 9 \\
\hline VERACRUZ & 30 & 10 & 20 & 5 & 15 \\
\hline YUCATÁN & 15 & 7 & 10 & 2 & 9 \\
\hline ZACATECAS & 18 & 9 & 12 & 5 & 14 \\
\hline TOTAL & 882 & 395 & 584 & 250 & 645 \\
\hline
\end{tabular}

Fuente: información de los Institutos Estatales Electorales.

Elaborado por: Autora.

*Las cifras corresponden a los procesos electorales estatales de los años 2014, 2015 y 2016. 
En la tabla que sigue se presentan los porcentajes correspondientes a cada principio de representación por entidad, mostrando que el $44.8 \%$ de las diputadas ocupan los puestos de mayoría relativa, mientras que el $42.8 \%$ lo hacen por representación proporcional, en total el porcentaje de diputadas corresponde a $44 \%$. Considerando estos tres datos podemos ver que el porcentaje de mujeres en las cámaras legislativas en total está por debajo de la paridad, sin embargo si vemos el detalle de cada entidad detectamos que hay entidades en las que se rebasa el 50\% de la participación de mujeres, estos son los casos de Campeche, Chiapas, Chihuahua y Querétaro.

Tabla 7.

Porcentaje de diputadas por entidad federativa y tipo de representación*

\begin{tabular}{lccc}
\hline \multicolumn{1}{c}{ ESTADOS } & $\begin{array}{c}\text { \% de } \\
\text { diputadas } \\
\text { de MR }\end{array}$ & $\begin{array}{c}\text { \% de } \\
\text { diputadas } \\
\text { de RP }\end{array}$ & $\begin{array}{c}\text { \% de diputadas en } \\
\text { la legislatura local }\end{array}$ \\
\hline AGUASCALIENTES & 61.1 & 22.2 & 48.2 \\
BAJA CALIFORNIA & 41.2 & 25.0 & 36.0 \\
BAJA CALIFORNIA & 43.8 & 60.0 & 47.6 \\
SUR & 57.1 & 57.1 & 57.1 \\
CAMPECHE & 51.4 & 50.0 & 50.8 \\
CHIAPAS & 59.1 & 36.4 & 51.5 \\
CHIHUAHUA & 50.0 & 44.4 & 48.0 \\
COAHUILA & 31.3 & 44.4 & 36.0 \\
COLIMA & 40.0 & 53.8 & 45.5 \\
DISTRITO FEDERAL & 46.7 & 40.0 & 44.0 \\
DURANGO & 42.2 & 30.0 & 37.3 \\
ESTADO DE MÉXICO & 45.5 & 42.9 & 44.4 \\
GUANAJUATO & 39.3 & 38.9 & 39.1 \\
GUERRERO & &
\end{tabular}




\begin{tabular}{llll} 
HIDALGO & 50.0 & 25.0 & 40.0 \\
JALISCO & 40.0 & 42.1 & 41.0 \\
MICHOACÁN & 45.8 & 37.5 & 42.5 \\
MORELOS & 16.7 & 83.3 & 43.3 \\
NAYARIT & 44.4 & 50.0 & 46.7 \\
NUEVO LEÓN & 38.5 & 37.5 & 38.1 \\
OAXACA & 44.0 & 41.2 & 42.9 \\
PUEBLA & 30.8 & 26.7 & 29.3 \\
QUERÉTARO & 53.3 & 50.0 & 52.0 \\
QUINTANA ROO & 53.3 & 30.0 & 44.0 \\
SAN LUIS POTOSÍ & 40.0 & 25.0 & 33.3 \\
SINALOA & 50.0 & 37.5 & 45.0 \\
SONORA & 42.9 & 33.3 & 39.4 \\
TABASCO & 28.6 & 50.0 & 37.1 \\
TAMAULIPAS & 40.9 & 50.0 & 44.4 \\
TLAXCALA & 26.7 & 50.0 & 36.0 \\
VERACRUZ & 33.3 & 25.0 & 30.0 \\
YUCATÁN & 46.7 & 20.0 & 36.0 \\
ZACATECAS & 50.0 & 41.7 & 46.7 \\
TOTAL & $\mathbf{4 4 . 8}$ & $\mathbf{4 2 . 8}$ & $\mathbf{4 4 . 0}$ \\
\hline
\end{tabular}

Fuente: www.ine.mx

Elaborado por: Autora.

*Las cifras corresponden a los procesos electorales estatales de los años 2014, 2015 y 2016.

De acuerdo con los cuatro rangos de porcentajes que se determinaron para el análisis de la presencia de mujeres en las cámaras legislativas estatales, se tiene que cuatro entidades cumplen con la paridad. Mientras que 16 están 
en un margen cercano a alcanzar la paridad (40-49\%) destacando los estados de Aguascalientes, Baja California Sur, Coahuila, Distrito Federal, Nayarit, Sinaloa y Zacatecas con cifras por encima de los 45 puntos porcentuales. En los doce estados restantes se registran porcentajes más lejanos a la paridad (25-39\%) siendo el estado de Puebla el más bajo con $29.3 \%$.

\section{Tabla 8.}

Distribución de la participación política de mujeres por rango y por tipo de representación

\begin{tabular}{lccc}
\hline \multirow{2}{*}{ RANGO } & \multicolumn{2}{c}{ NÚMERO DE ESTADOS } \\
& TOTAL MR-RP & MR & RP \\
\hline Más de $50 \%$ & 4 & 6 & 4 \\
$40-49 \%$ & 16 & 18 & 13 \\
$25-39 \%$ & 12 & 7 & 13 \\
Menos de 24\% & & 1 & 2 \\
\hline
\end{tabular}

Fuente: www.ine.mx

Elaborado por: Autora.

De acuerdo con el cuadro anterior, se observa que desagregando los porcentajes por principio de representación el estado de Morelos registra el porcentaje más bajo por mayoría relativa, mientras que los estados de Aguascalientes y Yucatán cuentan con los niveles más bajos en representación proporcional. Por el contrario, destacan los estados de Aguascalientes, Campeche, Chiapas, Chihuahua, Querétaro y Quintana Roo con los porcentajes más altos en mayoría relativa, mientras que las entidades de Baja California Sur, Campeche, Distrito Federal y Morelos tienen los niveles más altos en representación proporcional. Se observa que Campeche es el único estado que cuenta con la mayor participación de mujeres en el legislativo por los dos 
principios, superando en ambos la paridad.

A continuación se presenta el cuadro completo de rangos por cada principio y entidad, en el cual también podemos observar que coinciden cuatro estados entre los que registran los porcentajes más bajos en los dos principios de representación: Guerrero, Nuevo León, Puebla y Veracruz.

\section{Tabla 9.}

Participación política de las mujeres en los estados por rango y tipo de representación

\section{ESTADOS}

\section{RANGO}

TOTAL MR-RP

MR

RP

\begin{tabular}{|c|c|c|c|}
\hline $\begin{array}{c}\text { Más de } \\
50 \%\end{array}$ & $\begin{array}{l}\text { Campeche, Chi- } \\
\text { apas, Chihuahua y } \\
\text { Querétaro }\end{array}$ & $\begin{array}{c}\text { Aguascalientes, } \\
\text { Campeche, Chiapas, } \\
\text { Chihuahua, Querétaro } \\
\text { y Quintana Roo }\end{array}$ & $\begin{array}{c}\text { Baja California Sur, } \\
\text { Campeche, Distrito } \\
\text { Federal y Morelos }\end{array}$ \\
\hline $40-49 \%$ & $\begin{array}{l}\text { Aguascalientes, Baja } \\
\text { California Sur, Co- } \\
\text { ahuila, Distrito Fed- } \\
\text { eral, Durango, Gua- } \\
\text { najuato, Hidalgo, } \\
\text { Jalisco, Michoacán, } \\
\text { Morelos, Nayarit, } \\
\text { Oaxaca, Quintana } \\
\text { Roo, Sinaloa, Tam- } \\
\text { aulipas y Zacatecas }\end{array}$ & $\begin{array}{c}\text { Baja California, Baja } \\
\text { California sur, Coa- } \\
\text { huila, Distrito Federal, } \\
\text { Durango, Estado de } \\
\text { México Guanajuato, } \\
\text { Hidalgo, Jalisco, } \\
\text { Michoacán, Nayarit, } \\
\text { Oaxaca, San Luis Po- } \\
\text { tosí, Sinaloa, Sonora, } \\
\text { Tamaulipas, Yucatán y } \\
\text { Zacatecas }\end{array}$ & $\begin{array}{c}\text { Chiapas, Coahuila, } \\
\text { Colima, Durango, } \\
\text { Guanajuato, Jalisco, } \\
\text { Nayarit, Oaxaca, } \\
\text { Querétaro, Tabasco, } \\
\text { Tamaulipas, Tlax- } \\
\text { cala y Zacatecas }\end{array}$ \\
\hline
\end{tabular}




\begin{tabular}{|c|c|c|c|}
\hline $25-39 \%$ & $\begin{array}{c}\text { Baja California, } \\
\text { Colima, Estado de } \\
\text { México, Guerrero, } \\
\text { Nuevo León, Pueb- } \\
\text { la, San Luis Potosí, } \\
\text { Sonora, Tabasco, } \\
\text { Tlaxcala, Veracruz y } \\
\text { Yucatán }\end{array}$ & $\begin{array}{c}\text { Colima, Guerrero, } \\
\text { Nuevo León, Puebla, } \\
\text { Tabasco, Tlaxcala y } \\
\text { Veracruz }\end{array}$ & $\begin{array}{l}\text { Baja California, } \\
\text { Chihuahua, Estado } \\
\text { de México, Guerre- } \\
\text { ro, Hidalgo, Micho- } \\
\text { acán, Nuevo León, } \\
\text { Puebla, Quintana } \\
\text { Roo, San Luis Po- } \\
\text { tosí, Sinaloa, Sono- } \\
\text { ra y Veracruz }\end{array}$ \\
\hline $\begin{array}{c}\text { Menos de } \\
24 \%\end{array}$ & & Morelos & $\begin{array}{l}\text { Aguascalientes y } \\
\text { Yucatán }\end{array}$ \\
\hline
\end{tabular}

Fuente: www.ine.mx

Elaborado por: Autora.

Es importante destacar que la mayor presencia de mujeres en las cámaras legislativas locales se da a través del principio de mayoría relativa, con lo que se evidencia que por un lado, el efecto de la Ley de Paridad ha permitido que más mujeres compitan directamente en los distritos uninominales, obteniendo victorias importantes frente a sus opositores hombres. Por otro lado, se muestra que aunque los partidos podrían optar por repartir sus escaños de representación proporcional a más hombres, la ley los ha obligado a considerar también a las mujeres fomentando en todo momento la garantía de la participación política de las mujeres por igual. No obstante, es importante analizar las condiciones de competencia a las que se enfrentan las mujeres, sobre todo en aquellos estados en los que aún se registran bajos porcentajes de presencia de mujeres, para poder evidenciar las posibles barreras que impiden que más mujeres alcancen un escaño.

\section{Sistema de partidos y paridad}

Una vez que se han analizado de manera global los resultados electorales por entidad, es fundamental conocer cómo se han repartido estos espacios 
para las mujeres en cada uno de los partidos políticos por cada principio de representación, para de esta forma, poder identificar en qué fuerzas políticas se favorece más la presencia de mujeres y en cuáles no. En primer lugar, observamos de acuerdo con el gráfico siguiente que, el PAN cuenta con el mayor número de diputadas por mayoría relativa, le sigue el PRI y en tercer puesto se ubica la coalición PRI-PVEM.

\section{Gráfico 9.}

Diputadas por Mayoría Relativa

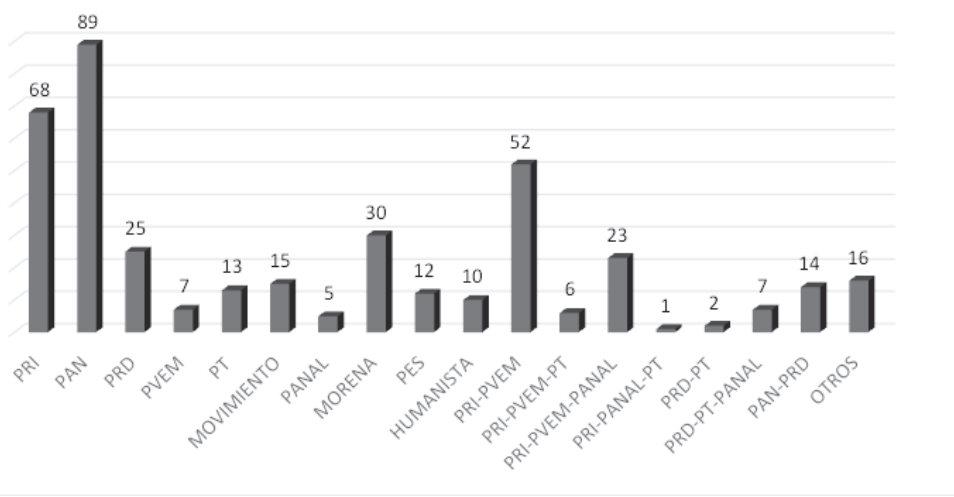

Fuente: www.ine.mx

Elaborado por: Autora.

Son dos los partidos que en solitario registran los números más bajos, estos son el PANAL y el PVEM, en contraste estas mismas fuerzas políticas en alianza con el PRI obtienen las cifras más altas de escaños para mujeres. Destaca la cantidad alcanzada por MORENA debido a que es un partido recientemente conformado, surgido de la escisión del PRD, el cual registra un número menor de diputadas con lo que se ve el grado de afectación para 
este partido producto de la división.

En lo que respecta al número de diputadas por el principio de representación proporcional se observa que, el PRI se ubica en la primera posición pero sólo por una diputada más respecto del PAN quien está en segundo lugar, en la siguiente posición se encuentra el PRD pero nuevamente muy cercano al recién conformado MORENA, el cual supo capitalizar la división y llevarse parte del electorado que apoyaba anteriormente a ese partido.

\section{Gráfico 10.}

Diputadas por Representación Proporcional

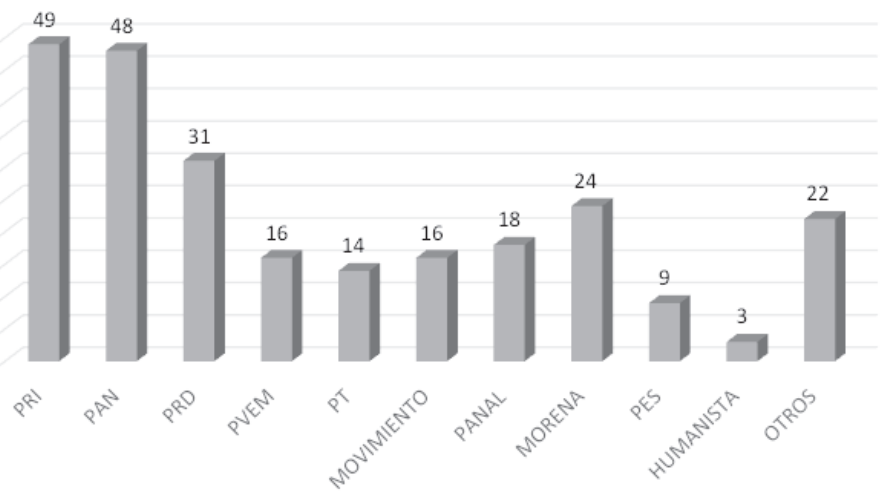

Fuente: www.ine.mx

Elaborado por: Autora. 


\section{Gráfico 11.}

Total de Diputadas por Partido Político (MR y RP)

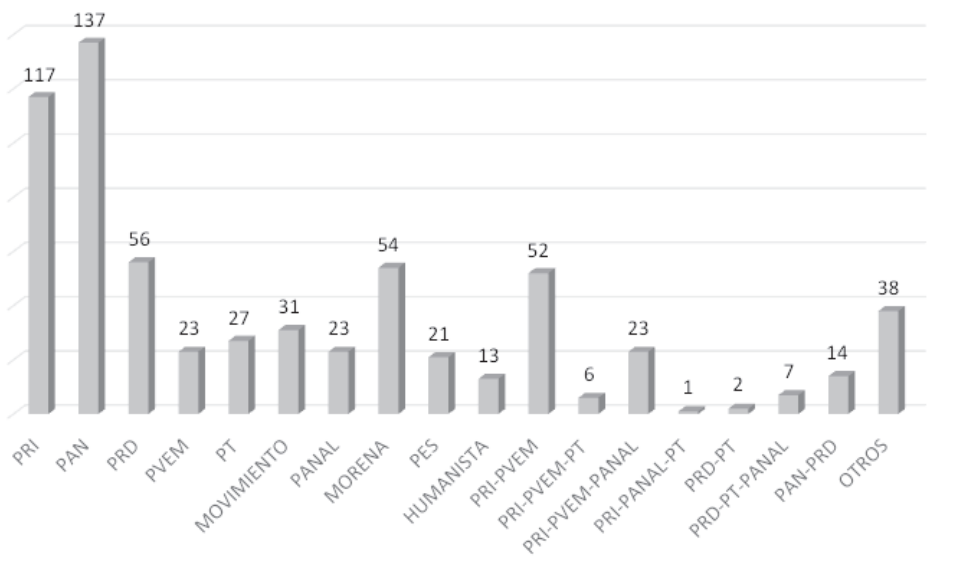

Fuente: www.ine.mx

Elaborado por: Autora.

Realizando la suma de los dos principios tenemos que el PAN es el partido que registra el mayor número de diputadas en los congresos locales, le sigue el PRI con veinte diputadas menos. En tercer lugar se ubica el PRD, muy por debajo de estos dos, y a penas con una diferencia de dos y cuatro diputadas correspondientes al cuarto y quinto lugar que ocupa MORENA y la coalición PRI-PVEM respectivamente.

Finalmente el gráfico siguiente nos muestra el total de diputadas por los dos principios de representación, tanto de los partidos políticos en solitario como de las distintas coaliciones. En este sentido, se evidencia que la confirmación del sistema de partidos a nivel local coincide con la del nivel nacional, al constituirse en un pluralismo limitado en el que prevalecen 
cuatro fuerzas políticas con fuerza electoral de importancia: PRI, PAN, PRD y MORENA, los cuales van acompañados del PVEM y el PANAL quienes sin coalición tendrían menos posibilidades de ocupar una posición representativa en los congresos locales.

Asimismo destaca que entre los partidos considerados pequeños, Movimiento Ciudadano en solitario alcanza un número considerable de diputadas, al igual que el Partido del Trabajo, no obstante su posición sigue siendo minoritaria en comparación con el PRI y el PAN quienes se constituyen como las primeras fuerzas partidarias en la mayoría de las entidades federativas. Resta esperar para los siguientes procesos electorales locales la permanencia de los tres partidos recientemente conformados, Movimiento de Regeneración Nacional, Partido Encuentro Social y Partido Humanista, así como la evolución de la aplicación de la Ley de Paridad en aquellos estados que aún registran bajos porcentajes y la consolidación en aquellos que ya conforman espacios legislativos partidarios. 
ELECCIONES EN MÉXICO 2015-2016: CONSTRUYENDO LA PARIDAD SUSTANTIVA

\section{Gráfico 12.}

Número de diputadas por partido político y tipo de representación

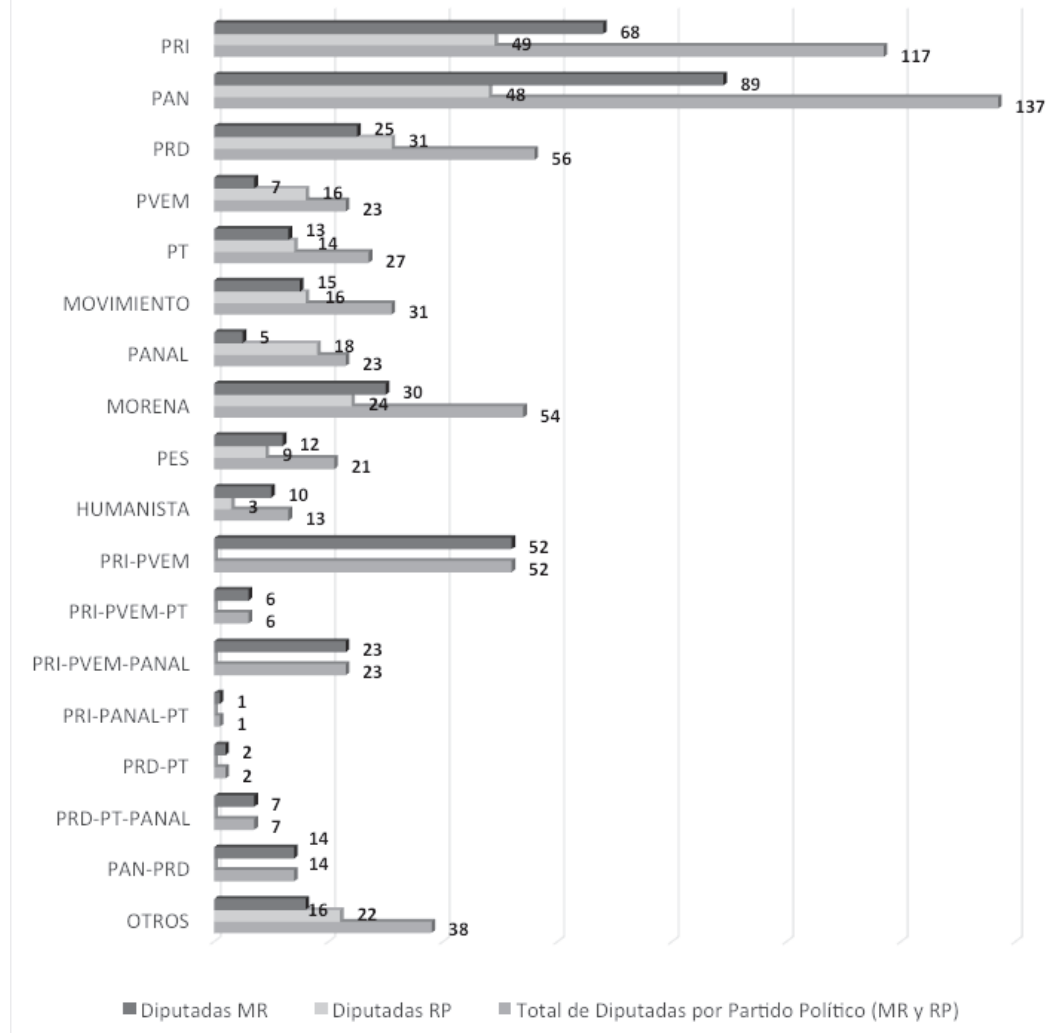

Fuente: www.ine.mx

Elaborado por: Autora. 


\section{Retos para alcanzar la paridad sustantiva}

En 2014 se promovió una reforma tanto constitucional como a la Ley General de Instituciones y Procedimientos Electorales (LEGIPE) que realizaba las siguientes modificaciones:

\section{$\underline{\text { Reforma constitucional: }}$}

Fracción I del artículo 41 constitucional, determina que, entre los fines de los partidos políticos, se encuentran el de promover la participación en la vida democrática y posibilitar el acceso de las y los ciudadanos al ejercicio del poder público de acuerdo con la paridad.

\section{Reforma a la LEGIPE:}

Artículo 7, párrafo 1 determina que es un derecho de las y los ciudadanos, así como una obligación de los partidos políticos, la igualdad de oportunidades y la paridad para el acceso a cargos de elección popular.

Luego de aprobada esta reforma se desarrollaron procesos electorales locales en 2015 y 2016 que evidenciaron la resistencia por parte de los partidos políticos a hacer efectiva la paridad, muestra de ello son los siguientes casos de violencia política de género y de los que da cuenta el Tribunal Electoral del Poder Judicial de la Federación (TEPJF, 2016): 
CHIAPAS: La candidata del PAN a la alcaldía del Municipio de Reforma, Yesenia Alamilla Vicente, fue agredida en un tramo carretero entre Reforma, Chiapas y Villahermosa, Tabasco. La candidata sufrió de golpes, insultos y fue encañonada por los sujetos que la atacaron.

CIUDAD DE MÉXICO: Dos colaboradores en la campaña de la candidata del Partido de la Revolución Democrática (PRD) a la jefatura delegacional, Ana Julia Hernández Pérez, fueron agredidos con armas de fuego dentro de su vehículo. Grupos de militantes del PRI y PRD se enfrentaron en la delegación Cuajimalpa, donde resultaron varios heridos, entre ellos el candidato a diputado del distrito XX local, Adrián Rubalcava, quien estuvo en terapia intermedia.

COLIMA: Durante el proceso electoral extraordinario de Colima se detectaron dos casos de robo de los paquetes electorales en casillas presididas por mujeres.

ESTADO DE MÉXICO: La candidata a la alcaldía de Ecatepec por el PT, Jessica Salazar, denunció que fue víctima de agresiones y amenazas, así como de un intento de secuestro el 11 de mayo en la colonia Alboradas de Aragón, donde un comando armado de 13 sujetos la agredió de manera física y verbal y dos de sus colaboradores resultaron heridos.

GUERRERO: La precandidata por el PRD, Aída Nava, fue encontrada decapitada en las inmediaciones del poblado de Tecoanapa, un día después de haber sido secuestrada durante un acto político. El candidato del Partido Revolucionario Institucional (PRI) a la presidencia municipal de Chilapa de Álvarez, Guerreo, Ulises Fabián Quiroz, fue asesinado por un grupo de hombres armados 
cuando se dirigía a un mitin en la comunidad de Atzacoaloya. La candidata a diputada por el Partido del Trabajo (PT), Silvia Romero Suárez, quien fue secuestrada el 12 de mayo de 2015, fue liberada por sus captores un día después. Cuando fue interceptada se encontraba en campaña electoral en los municipios de Arcelia y Tlapehuala.

MORELOS: La precandidata a la diputación federal por el PAN en Morelos, Gabriela Pérez Cano, sufrió un ataque en su domicilio. Durante los hechos los agresores se llevaron objetos de valor y documentos importantes. Además, dejaron un mensaje que decía "Abandona la candidatura" y agredieron a su hijo de 14 años. La camioneta en la que viajaba Mauricio Lara, candidato del Partido Socialdemócrata (PSD) a la Alcaldía de Emiliano Zapata, fue atacada a balazos por dos hombres. Gisela Mota, alcaldesa de Temixco fue asesinada un día después de asumir el cargo.

SONORA: En abril de 2015 aparecieron unas mantas con las frases "las mujeres como las escopetas, cargadas y en el rincón" y “La panocha en las coyotas, ino en palacio!", en alusión a la participación de las mujeres en la política.

Estos son sólo algunos ejemplos de actos de violencia política en contra de mujeres, de manera específica la Fiscalía Especializada para la Atención de Delitos Electorales reportó 38 casos de violencia política en contra de las mujeres en proceso electoral de 2015, ubicados principalmente en Baja California, Chiapas, Estado de México, Guerrero, Morelos, Oaxaca, Sonora y Tabasco, en contraste con los dos casos registrados oficialmente en 2012. Es importante considerar que no todos los casos de violencia se reportan de manera oficial, ya sea por falta de conocimiento en el procedimiento, por temor a mayores represalias o porque no se cuenta con la normativa que 
sancione estas faltas.

Debido a que no existe tipificación de la violencia política de género, el TEPJF determinó que las conductas que tuvieron lugar en dichos estados hicieron referencia a dos de los tipos penales previstos en el artículo 7 de la Ley General en Materia de Delitos Electorales (LGMDE):

Obstaculización o interferencia en el adecuado ejercicio de las tareas de las y los funcionarios electorales (fracción IV).

Realización de actos que provoquen temor o intimidación al electorado que atente la libertad del sufragio o perturbe el orden o el libre acceso de las y los electores a la casilla (fracción XVI).

Esto sin duda resultó insuficiente tanto para hacer justicia a las mujeres agredidas pero sobre todo evidenció la necesidad de generar marcos legales que prevegan, erradiquen y sancionen de manera específica la violencia política en contra de las mujeres. Todo ello, con el propósito de garantizar no sólo la participación política de las mujeres en las candidaturas, sino también su permanencia como autoridades electas, pues asimismo se han registrado casos de acoso político contra mujeres que ya ocupan cargos negándoles tomar posesión del cargo u obligándolas a renunciar.

Como se mencionó en un principio, si bien se ha podido registrar un aumento de mujeres en las cámaras legislativas tanto nacionales como locales, aún quedan vacíos legales que permiten no sólo evadir la norma de la paridad sino que buscan obstaculizar la participación política de las mujeres en condiciones equitativas, impidiendo la paridad sustantiva que va más allá del número de diputadas en los congresos, sino que impide a su vez que las mujeres en cargos públicos sean consideradas capaces de encabezar comisiones legislativas, establecer temas en la agenda política o presidir las 
cámaras, espacios que siguen siendo mayoritariamente dominados por los hombres.

Es por ello, que se requiere no sólo establecer cuanto antes una ley que prevenga, sancione y erradique los actos de violencia y acoso político contra las mujeres, la cual deberá venir acompañada de una normativa específica que regule al interior de los partidos políticos la participación equitativa y que impida que los recursos destinados para la capacitación y empoderamiento de la mujeres sea destinado para otros gastos como compra de mandiles o pago del evento de día de las madres. Asimismo se debe vigilar que las mujeres cuenten con el mismo financiamiento que los candidatos hombres para las campañas políticas y con el mismo tiempo de exposición en los diversos medios de comunicación.

En suma, para lograr una paridad sustantiva se requiere, entre otras cosas, que las iniciativas de ley en materia de violencia y acoso político identifiquen de manera clara quiénes son las víctimas (directas, indirectas y potenciales) para lo cual será necesario establecer mecanismos de recolección de información que permita establecer una base de datos sólida para la tipificación de este delito.

Es fundamental que se establezcan de manera explícita los tipos de sanción, que sean ejemplares y que se lleven a cabo para que se evite de manera real el ejercicio de la violencia política contra las mujeres. Involucrar a las diversas instituciones tanto públicas como privadas para hacer un frente común en contra de este tipo de violencia, y en especial a los organismos electorales sobre todo considerando que son éstos los que regulan la vida político electoral del país. Finalmente, generar y aplicar políticas integrales enfocadas en la prevención y erradicación de cualquier tipo de violencia contra las mujeres. 


\section{Bibliografía}

Aparicio Castillo, F. J. (2011). "Cuotas de género en México. Candidaturas y resultados electorales para diputados federales 2009”. En Revista Temas selectos de derecho electoral. México: TEPJF.

Aziz Nassif, A. (coord.). (2003). México al inicio del siglo XXI, democracia, ciudadanía y desarrollo. México: CIESAS-Miguel Ángel Porrúa.

Becerra, R. (et. al.). (2000). La mecánica del cambio político en México. Elecciones, partidos y reformas. México: Cal y Arena.

Cansino, C. (2000). La transición mexicana, 1977-2000. México: Centro de Estudios de Política Comparada.

Canterla, C. (2002). Mujer y derechos humanos: Universalismo y violencia simbólica de género. En M. Ramos, M. Vera. (Eds.) Discursos, realidades, utopías. La construcción del sujeto femenino en los siglos XIX y XX. Barcelona: Anthropos.

CEPAL. (2007). Objetivos de desarrollo del milenio, informe de 2006: una mirada a la igualdad entre los sexos y la autonomía de la mujer en América Latina y el Caribe. Recuperado de www.cepal.org el 14 de noviembre de 2016.

Córdova, L. (2008). La reforma electoral y el cambio político en México. México: UNAM-Instituto de Investigaciones Jurídicas.

Eisenstadt, T. (2004). Cortejando la democracia en México: estrategias partidarias e instituciones electorales. México: Colegio de México.

Elizondo, C. y B. Nacif. (comps.). (2002). Lecturas sobre el cambio político en México. México: CIDE-Fondo de Cultura Económica. 
Lamas, M. (1986). "La antropología feminista y la categoría género”. En Revista Nueva Antropología. México: Revista de Ciencias Sociales.

Ley General de Instituciones y Procedimientos Electorales

Ley General de Partidos Políticos

Luken, G. y V. Muñoz. (2003). Escenarios de la transición en México. México: Grijalbo.

Medina, A. (2010). La participación política de las mujeres. De las cuotas de género a la paridad. México: CEAMEG-H. Congreso de la Unión Cámara de Diputados LXI Legislatura.

Merino, M. (2003). La transición votada. México: Fondo de Cultura Económica.

Nohlen, D. (1994). Sistemas electorales y partidos políticos. México: FCEUNAM.

Pateman, C. (1995). El contrato sexual. Madrid: Anthropos.

Sartori, G. (2002). Partidos y sistemas de partidos. Madrid: Alianza Editorial.

TEPJF. (2016). Protocolo para atender la violencia política contra las mujeres. México: TEPJF. 